\title{
User's Manual for the Data Acquisition System for Monitoring the Fuel Oil Spill at the Sandia National Laboratories Installation in Livermore, California
}

by M.A. Widing and C.C. Leser

Decision and Information Sciences Division and Environmental Research Division

Argonne National Laboratory, 9700 South Cass Avenue, Argonne, Illinois 60439

April 1995

Work sponsored by Sandia National Laboratories, California

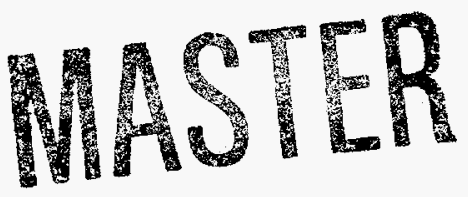




\section{DISCLAIMER}

This report was prepared as an account of work sponsored by an agency of the United States Government. Neither the United States Government nor any agency thereof, nor any of their employees, make any warranty, express or implied, or assumes any legal liability or responsibility for the accuracy, completeness, or usefulness of any information, apparatus, product, or process disclosed, or represents that its use would not infringe privately owned rights. Reference herein to any specific commercial product, process, or service by trade name, trademark, manufacturer, or otherwise does not necessarily constitute or imply its endorsement, recommendation, or favoring by the United States Government or any agency thereof. The views and opinions of authors expressed herein do not necessarily state or reflect those of the United States Government or any agency thereof. 


\section{DISCLAIMER}

Portions of this document may be illegible in electronic image products. Images are produced from the best available original document. 


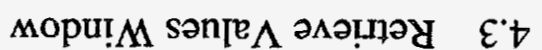

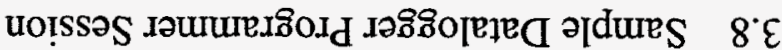

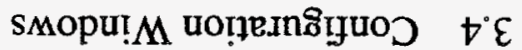

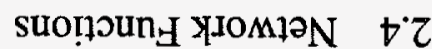




\section{CONTENTS (Cont.)}

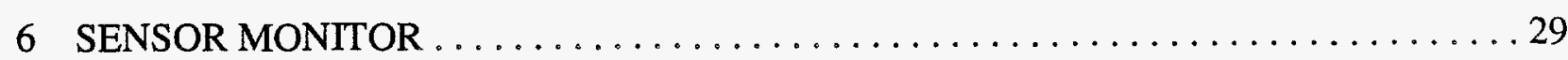

6.1 Sensor Monitor Overview . . . . . . . . . . . . . . . . . . . . . . 29

6.2 Sensor Monitor Window . . . . . . . . . . . . . . . . . . . . . . 29

APPENDIX: Julian Day Conversion Tables $\ldots \ldots \ldots \ldots \ldots \ldots \ldots \ldots \ldots \ldots$

\section{FIGURES}

$1.1 \quad$ Data Flow Diagram $\ldots \ldots \ldots \ldots \ldots \ldots \ldots \ldots \ldots \ldots \ldots \ldots \ldots \ldots \ldots \ldots \ldots$

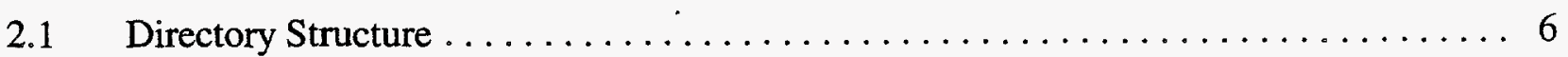

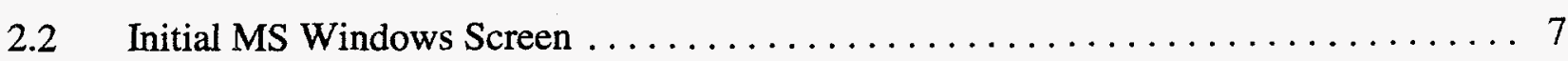

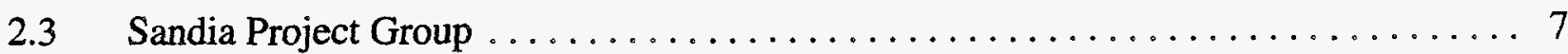

2.4 Standard Data Acquisition Screen Image $\ldots \ldots \ldots \ldots \ldots \ldots \ldots \ldots$

3.1 Datalogger Programmer Main Window $\ldots \ldots \ldots \ldots \ldots \ldots \ldots \ldots \ldots \ldots \ldots \ldots$

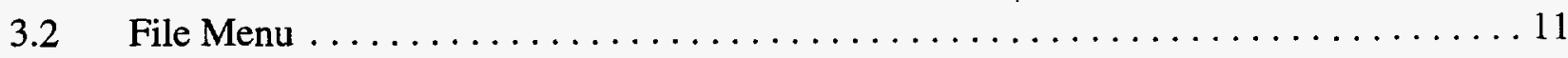

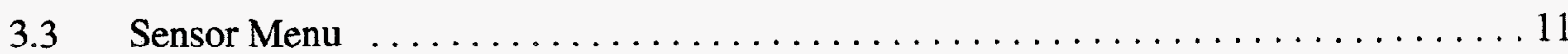

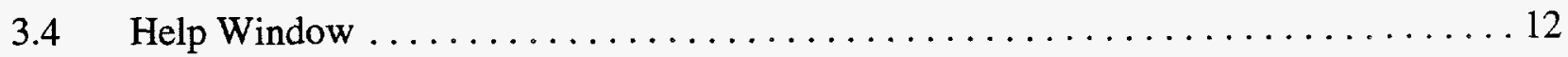

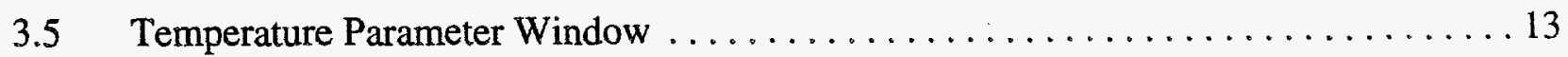

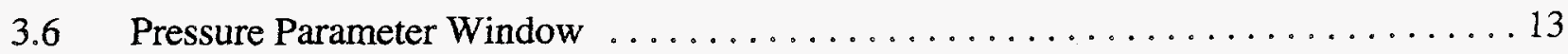

3.7 Tensiometer Parameter Window $\ldots \ldots \ldots \ldots \ldots \ldots \ldots \ldots \ldots \ldots \ldots \ldots \ldots \ldots \ldots \ldots \ldots$

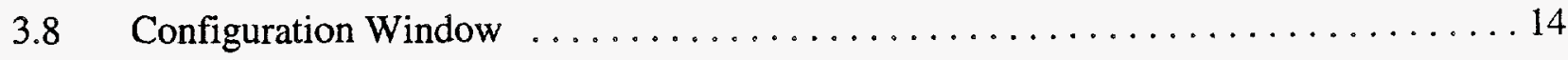

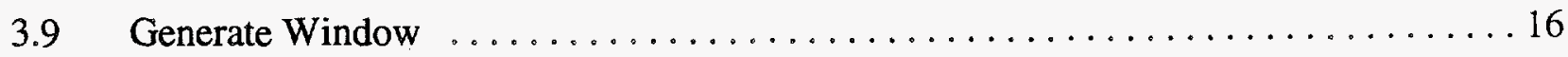

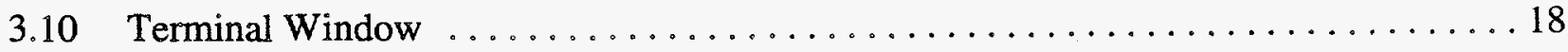

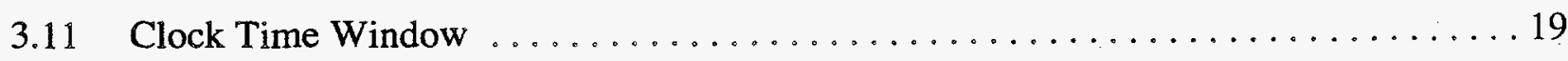




\section{FIGURES (Cont.)}

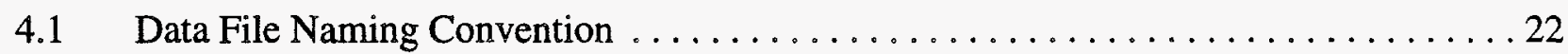

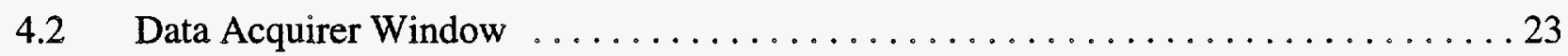

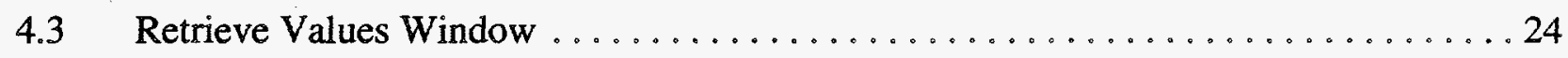

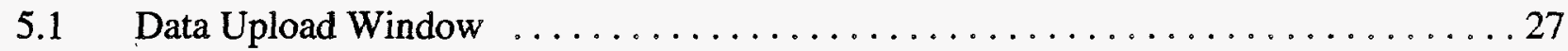

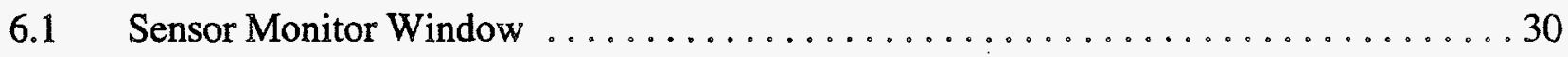

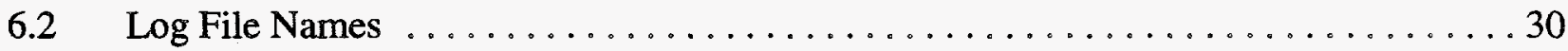

\section{TABLES}

A.1 Julian Calendar for Nonleap Year $\ldots \ldots \ldots \ldots \ldots \ldots \ldots \ldots \ldots \ldots \ldots \ldots$

A.2 Julian Calendar for Leap Year $\ldots \ldots \ldots \ldots \ldots \ldots \ldots \ldots \ldots \ldots \ldots \ldots \ldots \ldots$ 


\title{
USER'S MANUAL FOR THE DATA ACQUISITION SYSTEM FOR MONITORING THE FUEL OIL SPILL AT THE SANDIA NATIONAL LABORATORIES INSTALLATION IN LIVERMORE, CALIFORNIA
}

by

\author{
M.A. Widing and C.C. Leser
}

\begin{abstract}
This report describes the use of the data acquisition software developed by Argonne National Laboratory and installed at the fuel oil spill site at Sandia National Laboratories. This software provides various programs for interacting with the monitoring and logging system that collects electronic data from sensors installed downhole in the study area. This manual provides basic information on the design and use of these user interfaces, which assists the site coordinator in monitoring the status of the data collection process. Four software programs are included in the data acquisition software suite to provide the following capabilities: datalogger interaction, file management, and data security.
\end{abstract}

\section{INTRODUCTION}

\subsection{PURPOSE}

This manual describes the design and use of the data acquisition system that will monitor the collection of physical data at the fuel oil spill site at the Sandia National Laboratories (SNL) installation in Livermore, California. This manual is intended to be used as a reference guide for the site coordinators at the SNL site.

\subsection{OVERVIEW OF THE DATA ACQUISITION AND MANAGEMENT SYSTEM}

As part of an ongoing bioremediation study, Argonne National Laboratory (ANL) developed a data acquisition and management system to support data collection and analysis from 
downhole sensors at a fuel oil spill site. The overall design, quality assurance practices, and testing procedures used in this effort are described in the following documents:

- Remedial Action Plan for the Fuel Oil Spill at Sandia National Laboratories, Livermore, Argonne National Laboratory, Argonne, Ill., for the U.S. Department of Energy, Washington, D.C. (July 1992).

- Draft Report: Work Plan for the Fuel Oil Spill at Sandia National Laboratories, Livermore, Argonne National Laboratory Report, Argonne, Ill. (June 4, 1993).

- Quality Assurance Plan for the Data Acquisition and Management System for Monitoring the Fuel Oil Spill at the Sandia National Laboratories Installation in Livermore, California, ANL/ER-DIS/TM-4, Argonne National Laboratory, Argonne, Ill. (April 1995).

- Test Plan for the Data Acquisition and Management System for Monitoring the Fuel Oil Spill at the Sandia National Laboratories Installation in Livermore, California, ANL/ER-DIS/TM-1, Argonne National Laboratory, Argonne, Ill. (April 1995).

As detailed in the aforementioned documents, three subsystems were developed to support data management at the site: (1) a monitoring and logging subsystem, (2) a data acquisition subsystem, and (3) a data analysis subsystem. This manual addresses the software suite provided in the data acquisition subsystem.

\subsection{DATA ACQUISITION SUBSYSTEM}

As shown in Figure 1.1, the data acquisition subsystem plays an integral role in the flow of physical sensor data in the data management system. Three subunits of the monitoring system collect data from 51 pressure sensors installed downhole, 50 temperature probes installed downhole, and seven tensiometers installed in shallow boreholes throughout the pilot study area.

To interface with the electronic monitoring subsystem, the data acquisition subsystem uses a hardware system consisting of a ZEOS 486 personal computer (PC) with several additional hardware components. A mirrored hard-drive card with two 500-M drives provides added security: the computer would continue to operate even if one drive were to fail. A Digiboard communications board allows multiple serial ports to be available for interfacing with the data loggers through short-haul modems. The availability of multiple serial ports gives added flexibility to the system and provides a backup if one port were to fail. An Ethernet card provides a communications link to the data analysis subsystem for data transfer and printing. A tape system with a commercial backup 
Physical Samples

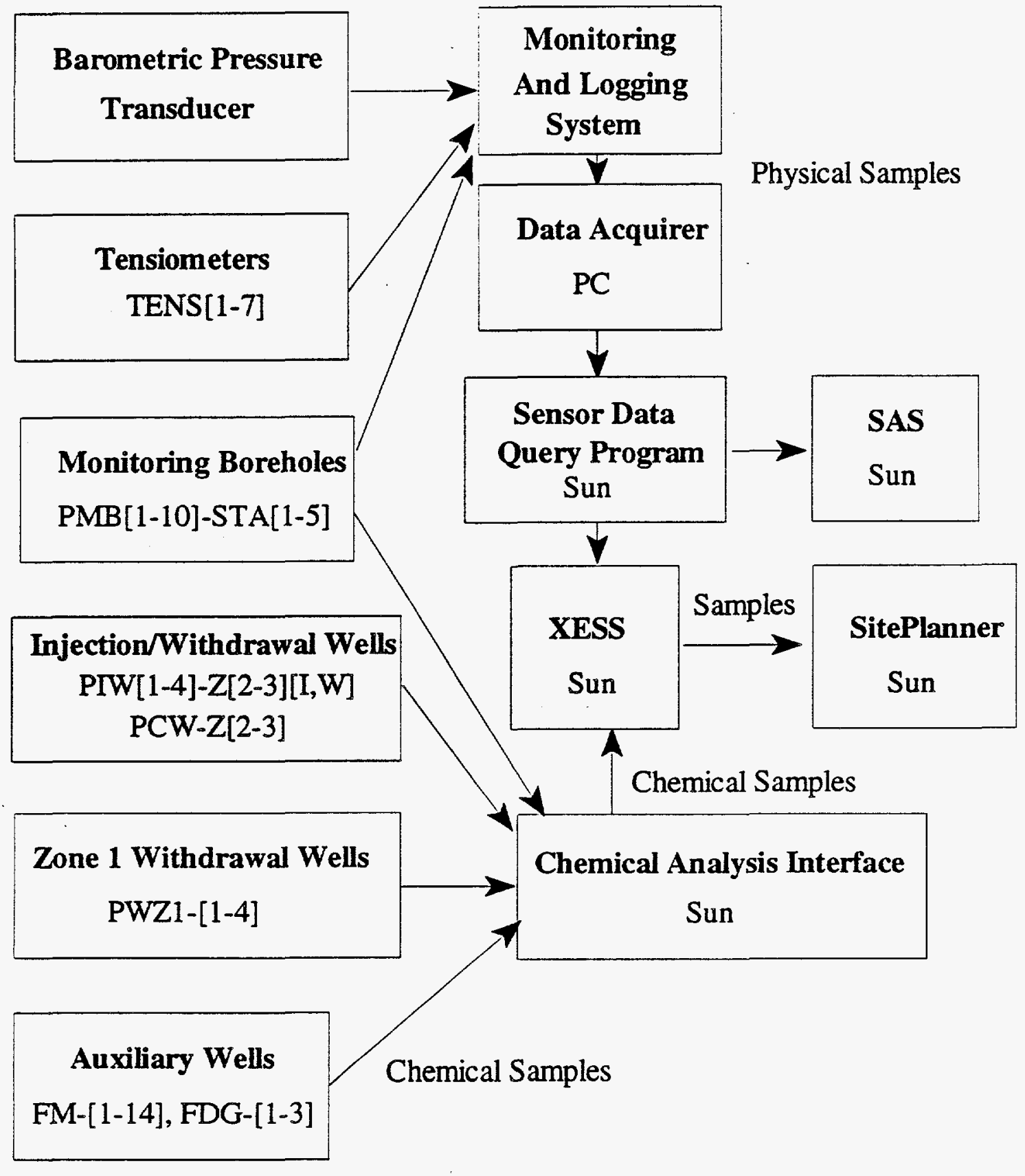

FIGURE 1.1 Data Flow Diagram 
program provides data backup functions. Finally, an uninterruptible power supply (UPS) with a telephone notification system provides power for limited amounts of time.

To interface with this hardware, a software suite was formed by using commercial software and custom interfaces created with ANL-developed application development libraries. The commercial software includes Microsoft (MS) Windows, the Conner Backup Exec program, and PC-NFS network software. Specific details on these programs are not given in this manual.

This manual documents the user interfaces of the four custom software programs used in the data acquisition system. The Datalogger Programmer assists the user in developing CR10 programs and sending them to the dataloggers. The Data Acquirer automatically retrieves the data values from the dataloggers, records them in the data directory, and copies them to the data analysis system. The Data Upload program can be used to manually copy files to the data analysis system, if necessary. The last software program, the Sensor Monitor, reports possible error conditions to the user.

\subsection{ORGANIZATION}

The remainder of this manual is organized as follows. Section 2 provides background information on the data acquisition software system, including a brief description of the use of the MS Windows environment. Directory structure, network interfaces, and commercial software use are discussed in this section. Section 3 discusses the Datalogger Programmer software and how to interact with the monitoring subsystem. Section 4 discusses the Data Acquirer program and how to start the data collection process. Finally, Sections 5 and 6 discuss the two small utilities provided on the system: the Data Upload and the Sensor Monitor. 


\section{DATA ACQUISITION SOFTWARE}

\subsection{DATA ACQUISITION SOFTWARE ORGANIZATION}

The data acquisition system resides on a PC that uses the DOS operating system in an MS Windows environment. All actions performed on the data acquisition computer should be logged in the computer trailer log book. After the computer is booted, the system will automatically attempt to connect to a TCP/IP network and prompt you for the appropriate password. You can then start MS Windows by entering the following command at the DOS prompt:

\section{win<Enter $>$}

All functions needed for the data acquisition system can be performed within MS Windows. If a power outage continues for a time that is longer than can be supported by the UPS, reboot the computer as directed above and ensure that the proper programs are running, as described in Section 2.2. There should be no reason to use the computer outside the MS Windows environment. The data acquisition computer should be a dedicated machine; it should not be used for other activities because the automated recording of data could be seriously affected. Any problems with the data acquisition computer should immediately be logged and reported.

The hard drives on the data acquisition computer are divided into two drives labeled "c" and "d." The "c" drive is mirrored and contains all data and active programs. If a mirrored drive fails, a message will be displayed when the machine is rebooted. The " $\mathrm{d}$ " drive contains maintenance files, such as the compiler and software development directories. Under normal system operation, only the data drive is accessed. The "d" drive is used only if a software program requires updating. Figure 2.1 shows the layout of the data directory on the "c" drive. As shown in the figure, the data directory contains copies of (1) active programs ending with the extension ".exe"; (2) CR10 programs ending with ".prg"; and (3) data files for pressure, temperature, and tensiometer data.

\subsection{MS WINDOWS ENVIRONMENT}

Under normal operation, the data acquisition computer runs under MS Windows. The Initial MS Windows Screen is similar to that shown in Figure 2.2. The window for the Clock accessory displays the time in Greenwich Mean Time (GMT). To ensure that data files have a standard reference time, the computer time should remain in GMT and should not be set to local time. 


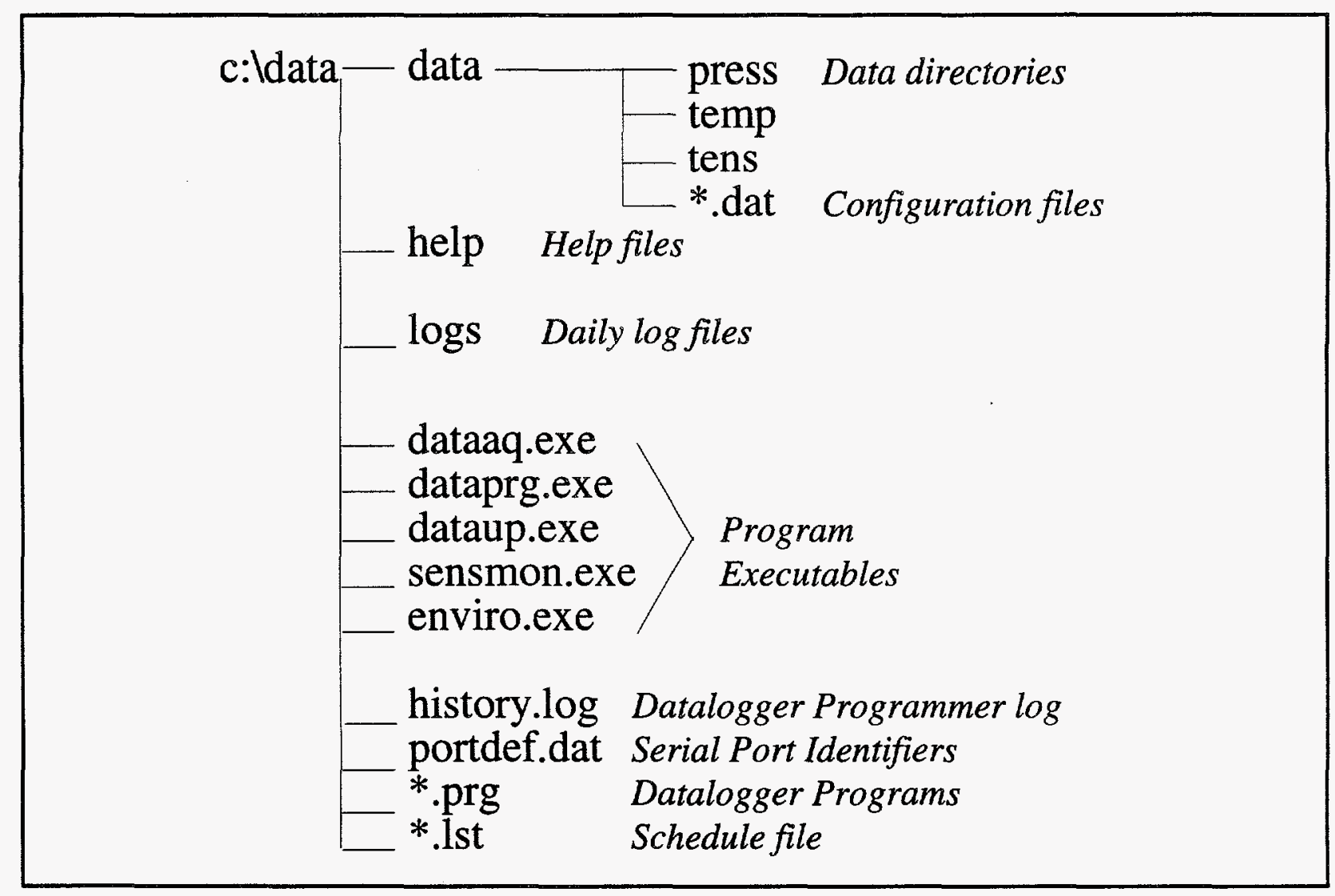

FIGURE 2.1 Directory Structure

The MS Windows Screen also contains the window for Program Manager, which controls the execution of programs under MS Windows. The group labeled "Sandia Project" contains the programs described in Sections 3 through 7. When you enter MS Windows, make sure the Conner Backup Exec Launcher icon is visible on the screen. This icon signifies that the backup program is running. Other programs that are generally running are the Data Acquirer and Sensor Monitor (refer to Sections 4 and 6). If the machine is rebooted, make sure these programs are running so the data acquisition computer is in its normal state. To start an application, double-click on the icon for that program in the Sandia Project Group. Figure 2.3 shows the icons for each data acquisition program. When all the applications are running, the screen looks similar to Figure 2.4.

To close an application into an icon, click on the down arrow in the upper right corner of the window. The program will continue to run. To open the program icon into a regular-size window, double-click on the icon. Windows can be moved on the screen by dragging the left mouse button while the pointer is over the top bar on the window. To quit an application, use either the quit button or the exit option in the default menu of the window. If you need to exit MS Windows, select the Exit Windows option in the default menu of the Program Manager. For more information on 


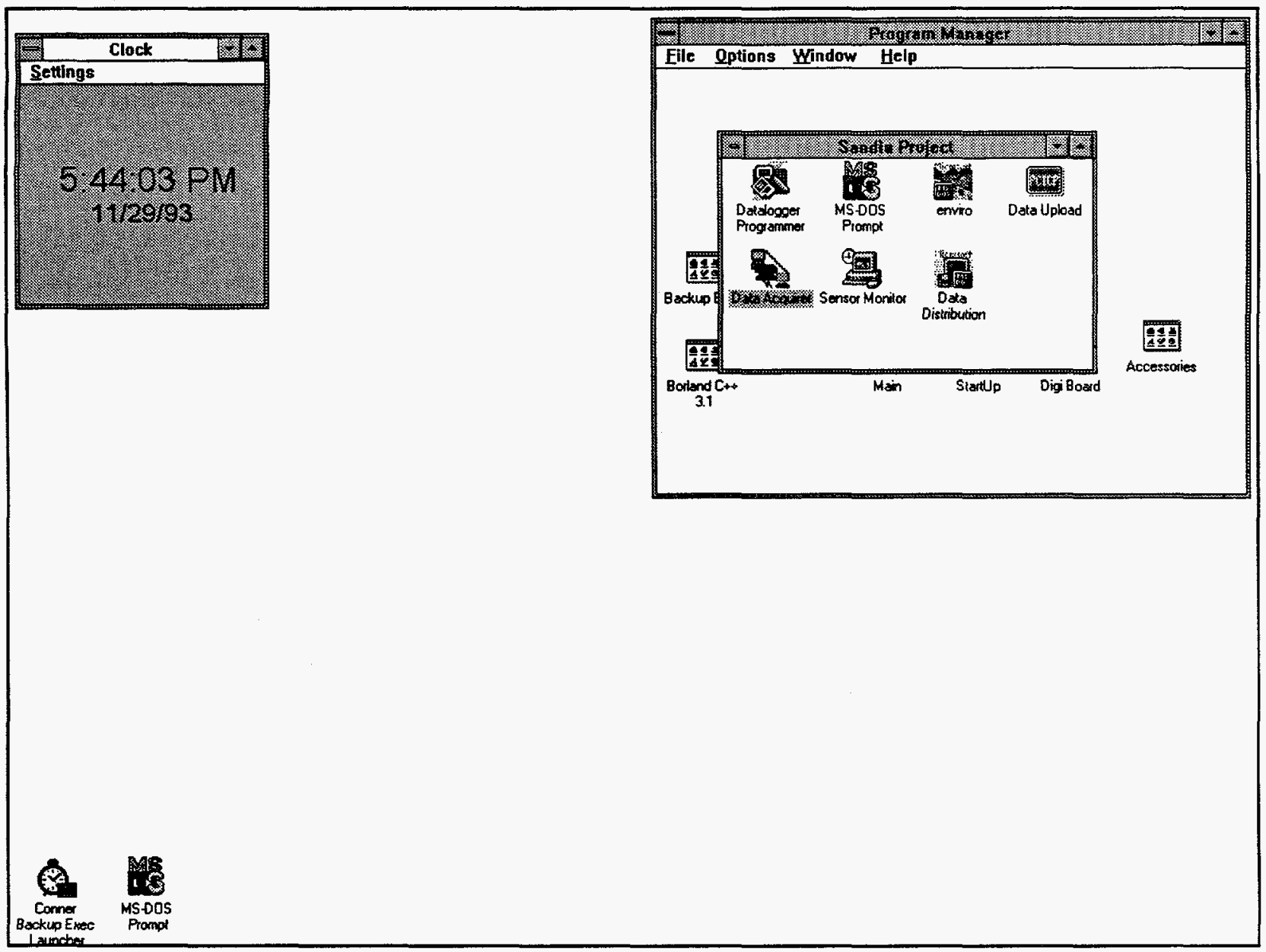

FIGURE 2.2 Initial MS Windows Screen

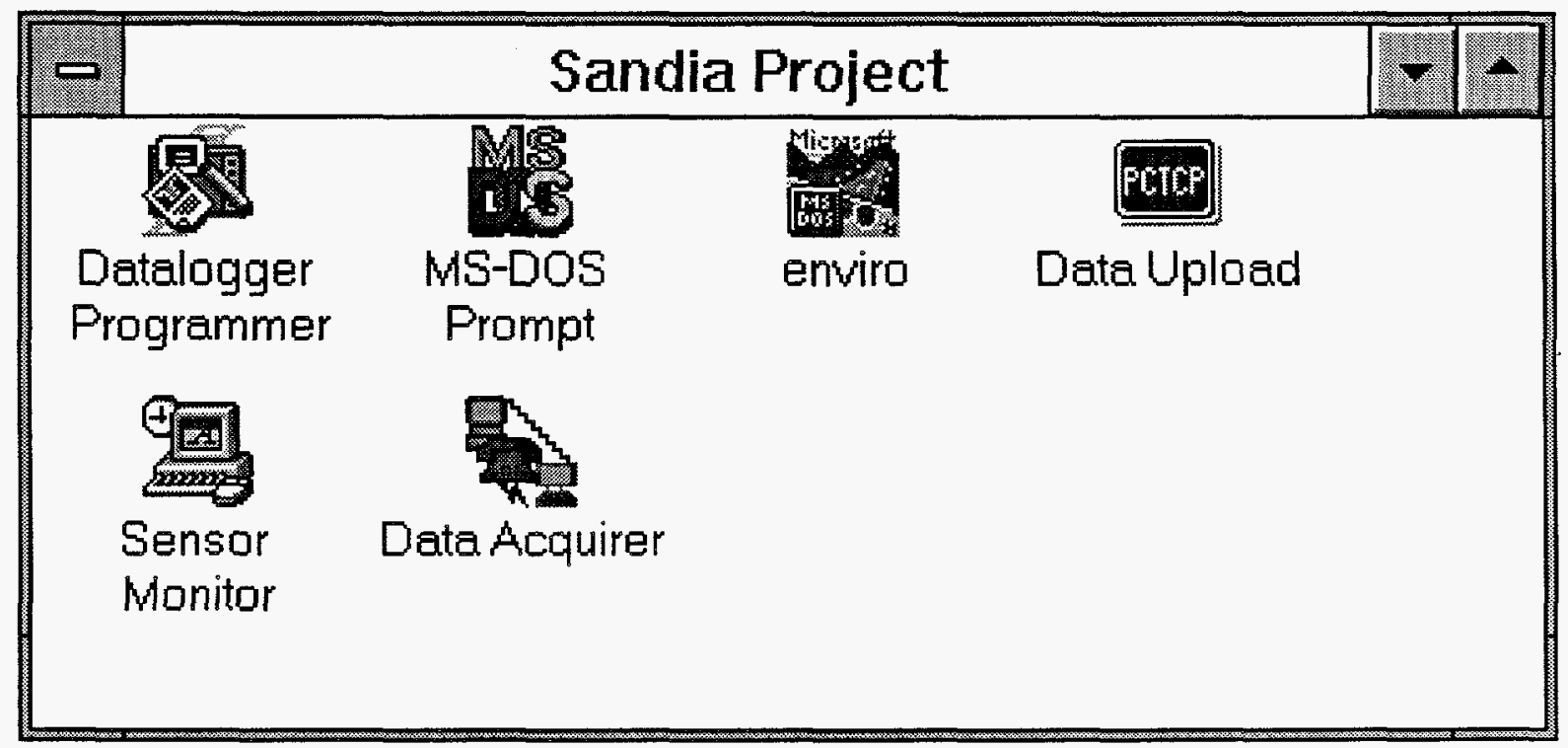

FIGURE 2.3 Sandia Project Group 


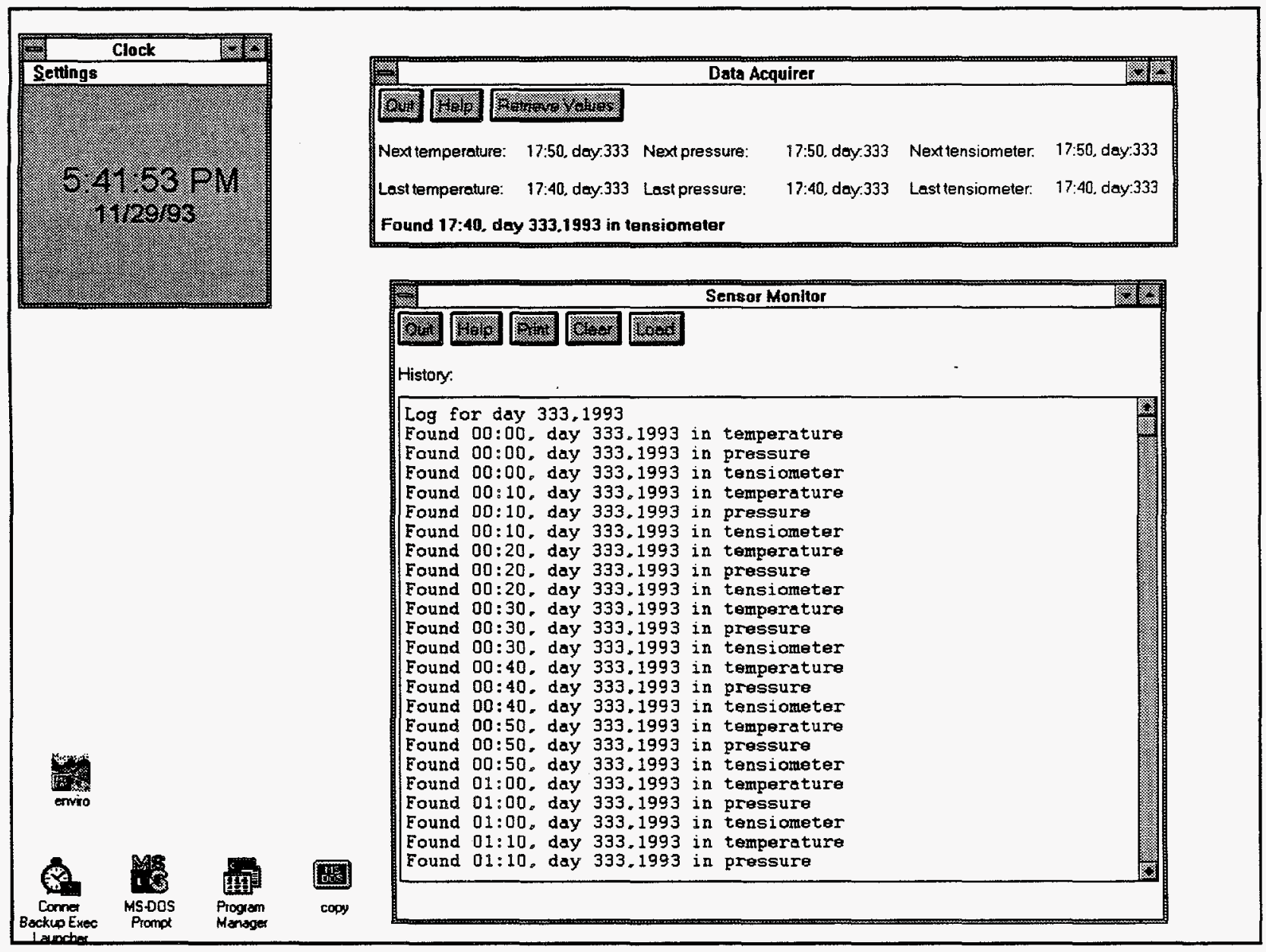

\section{FIGURE 2.4 Standard Data Acquisition Screen Image}

the use of MS Windows, consult the manuals in the computer trailer. After you exit MS Windows, the machine can be rebooted by using the reset button.

All of the applications in the data acquisition suite were developed by using the same application development library for consistency. The following text-editing standards are used in all ANL-developed software in both the data acquisition and data analysis software suites:

Enter

Press the Enter key to move from one text field to the next. In a table, press this key to move down to the next row in that column.

Shift-Enter Press the Shift key in combination with the Enter key to move to the previous item. In a table, press these keys to move to the previous row in that column.

Tab

Press the Tab key to move to the next column in a table. column in a table. 
Delete Press the Delete key to clear out one character in a text field.

Shift-Delete Press the Shift key in combination with the Delete key to clear out all of the characters in a text field in a table.

Esc

Press the Esc key to revert a text field value back to the last entered value.

\subsection{BACKUP SCHEDULE}

The Conner Backup Exec program automatically backs up the data directories on the PC. The program is configured to perform daily incremental backups and weekly full backups of the data directories. Weekly backups are performed on Sunday evenings. Backups are set to run each day at 0:30 GMT, a time chosen so that backups would not conflict with other actions on the PC. Every Monday morning, the site coordinator should label a new tape, replace the existing tape in the PC with the new one, store the previous tape in a safe location, and log the action in the trailor log book. The Conner Backup Exec program can be used to verify the contents of a tape. Whenever you use the Conner Backup utilities, make sure the Conner Backup Exec Launcher is running correctly on the PC after you have completed your actions. If this procedure is not done, the backups may not perform properly. For more information on the backup program, consult the Conner Backup Exec manuals in the computer trailer.

\subsection{NETWORK FUNCTIONS}

The PC-NFS network program connects the data acquisition computer to the data analysis computer. The data acquisition suite uses this link internally to transfer files and print the daily log file from the PC. Any problems with the PC-NFS link should be logged and reported. For example, if the PC stops functioning while a copy icon is displayed, there may be a problem with the PC-NFS connection. To print a file, use the "net print" command from a DOS shell tool rather than the standard DOS "print" command to avoid conflicts with the network. Additional information on PC-NFS can be found in the PC-NFS manuals in the computer trailer. 


\section{DATALOGGER PROGRAMMER}

\subsection{DATALOGGER PROGRAMMER OVERVIEW}

The Datalogger Programmer assists the user in developing CR10 datalogger programs and sending them to the monitoring and logging subsystem. Three different datalogger subunits are used to read the three different types of sensors: (1) temperature thermistors for temperature readings, (2) pressure transducers for pressure readings, and (3) tensiometers for soil moisture suction values. The CR10 dataloggers are normally programmed in a low-level language similar to assembly language. The Datalogger Programmer was developed to assist in configuring the dataloggers. Through the use of this interface, the task of programming the dataloggers is simpler and less susceptible to errors.

The Datalogger Programmer is the first step in starting the process of collecting data from the pilot study area. It supports four main tasks: (1) specifying the location of specific sensors, (2) programming the dataloggers, (3) sending programs to the datalogger, and (4) creating a file listing when readings are scheduled.

\subsection{DATALOGGER PROGRAMMER WINDOW}

The Datalogger Programmer is a MS Windows application with several windows that can be invoked from a main window through the use of a menu bar. Before starting the Datalogger Programmer, stop the Data Acquirer program, which also interfaces with the dataloggers through the serial ports of the PC (Section 4.2). This action will ensure that there is no conflict between the two programs. To start the Datalogger Programmer, double-click on the corresponding icon in the Sandia Project Group window in the Program Manager (Figure 2.3). The window shown in Figure 3.1 will appear. The text area in this main window provides a history of actions performed in that Datalogger Programmer session and serves as a quick check of whether the required steps have been done for each of the three subunits. You may also add your own notes to this text area. After reprogramming the subunits, save this log, which can then be printed and included in the log book.

The first option in the menu bar of this window is File. The File menu contains the options shown in Figure 3.2 and described below. The options perform the following actions:

Save Times Select this option to save the schedule listing of when each datalogger will be first accessed and what the sampling period will be.

Clear History Select this option to clear out the history text in the window. 


\begin{tabular}{|c|c|}
\hline Datalogger Programmer & 2 \\
\hline File Temperature Pressure & \\
\hline \multicolumn{2}{|l|}{ History: } \\
\hline $\begin{array}{l}\text { Parameter window displayed for Pressure subunit. } \\
\text { Canfiguration window displayed far Pressure subunit. } \\
\text { Parameter window displayed for Pressure subunit. } \\
\text { Parameter window displayed for Tensiometer subunit. } \\
\text { Configuration windaw displayed far Tensiometer subunit. } \\
\text { Generate window displayed for Pressure subunit. } \\
\text { Terminal window displayed for Pressure subunit. } \\
\text { Clack Time window displayed for Pressure subunit. } \\
\text { Successfully sent program to Pressure subunit. } \\
\text { Next reading for Pressure subsystem is scheduled for } \\
17: 25333,1993 \text { in time intervals of } 10 \text { minutes. } \\
\mid\end{array}$ & 2. \\
\hline
\end{tabular}

FIGURE 3.1 Datalogger Programmer Main Window

Save History Select this option to save the history text to the file history.log.

Close Select this option when you have completed a session of datalogger programming and wish to exit the program.

The next three options in the menu bar - Temperature, Pressure, and Tensiometer relate to the three sensor subunit types. For each sensor, you may choose any of the options shown in Figure 3.3. These options perform the following actions:

Parameters

Select this option to view the calibration parameters for each sensor. The window discussed in Section 3.3 will appear on the screen.

\begin{tabular}{|l|}
\hline File \\
\hline Save Times \\
Clear history \\
Save History \\
\hline Close \\
\hline
\end{tabular}

FIGURE 3.2 File Menu

\begin{tabular}{|l|}
\hline Temperature \\
\hline Parameters \\
Configuration \\
Generate \\
Ierminal \\
\hline
\end{tabular}

FIGURE 3.3 Sensor Menu 
Configuration

Generate
Select this option to view the relationship between each sensor and its well, station, and multiplexer location. The window discussed in Section 3.4 will appear on the screen.

Select this option to create a datalogger program with a specified sampling period and start time. The window discussed in Section 3.5 will appear on the screen.

Terminal

Select this option to program the datalogger for the indicated subunit.

The Help option on the menu bar brings up the Help window, with information as shown in Figure 3.4. This window is used throughout the data acquisition programs to display help information.

\subsection{PARAMETER WINDOWS}

The Parameter windows display the serial number and calibration values, if any, for each sensor. The window is different for each of the three subunits because the different types of probes differ electronically. Figures 3.5, 3.6, and 3.7 show the Parameter windows for the three types of sensors. In the unlikely event that these values need to be changed, you can edit the files "presspar.dat," "temppar.dat," and "tenspar.dat" by using an ASCII editor in a DOS shell tool.

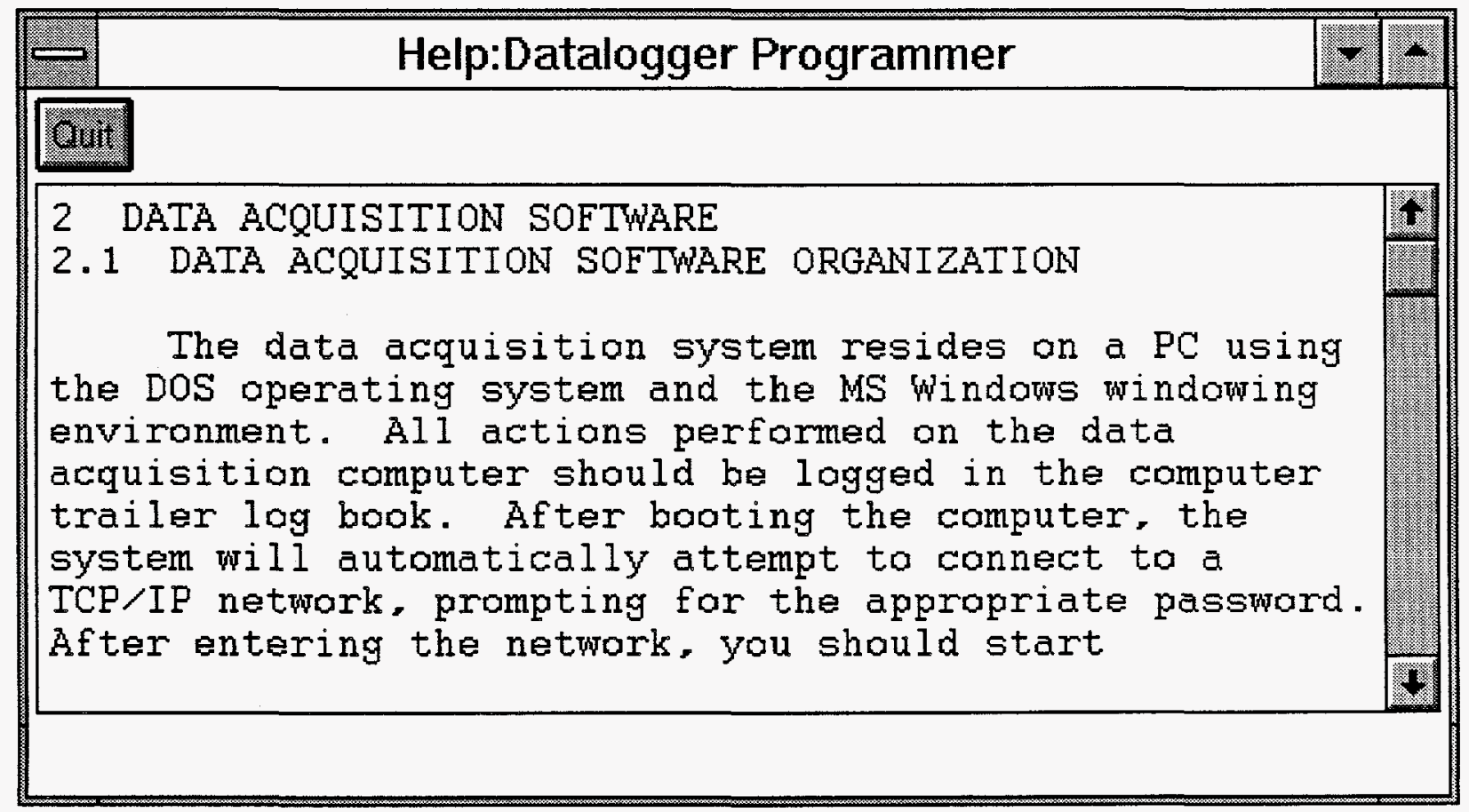




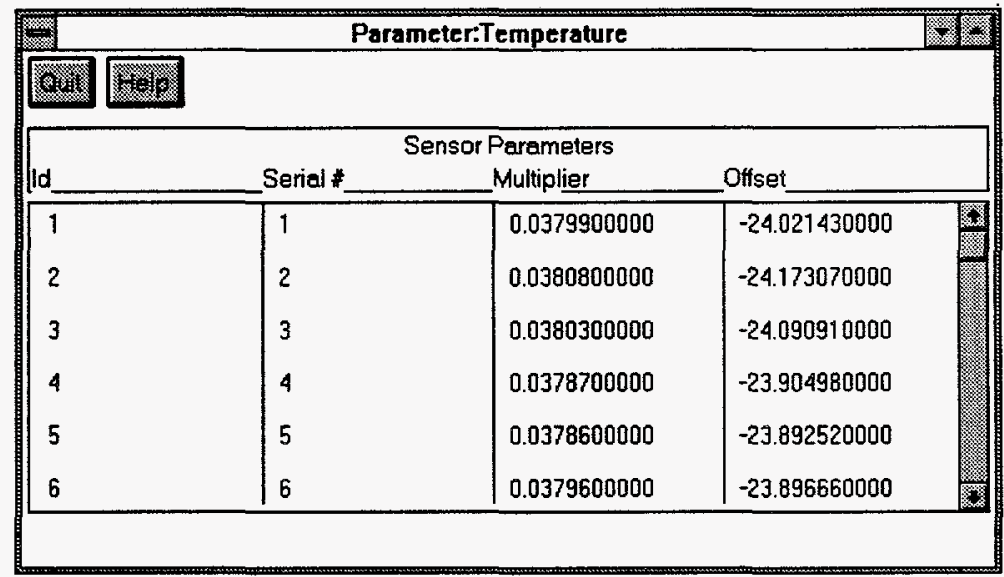

FIGURE 3.5 Temperature Parameter Window

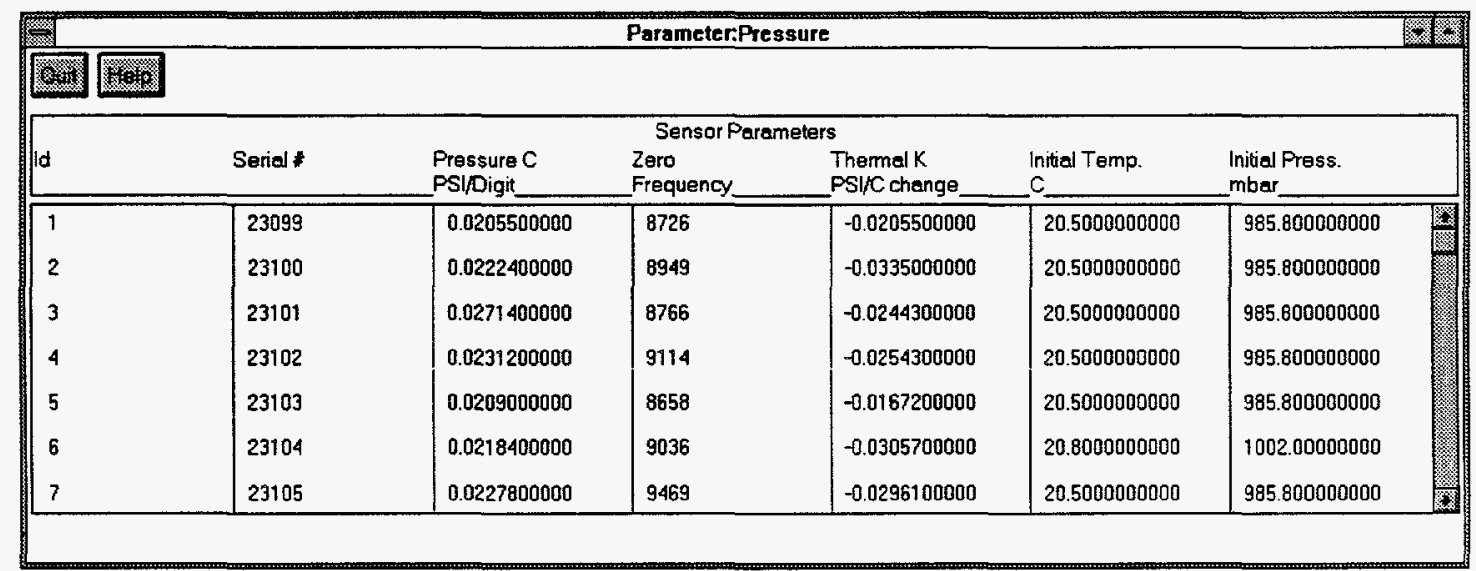

\section{FIGURE 3.6 Pressure Parameter Window}

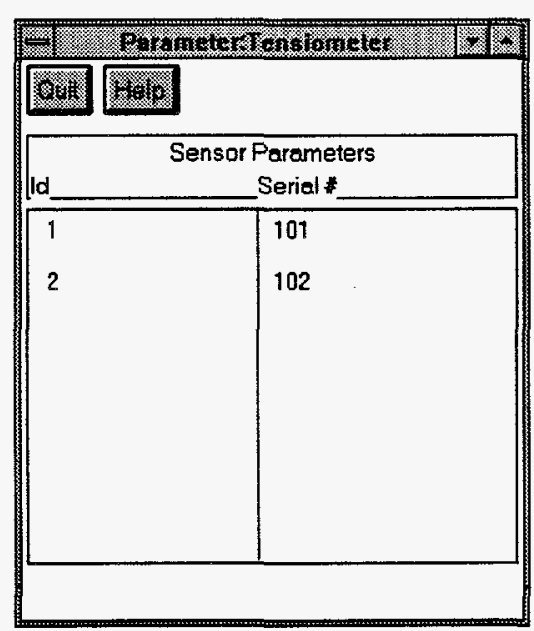

FIGURE 3.7 Tensiometer

Parameter Window 
The two buttons on this window perform the following actions:

Quit

Press this button to exit this window.

Help

Press this button to bring up the Help window with information on the Parameter window.

\subsection{CONFIGURATION WINDOWS}

Each sensor in a subunit is located at one station at one well. To correctly record the data, the software requires identification numbers for the sensors. The program also needs the number of the multiplexer and channel location to which each sensor is connected so it can generate the correct datalogger program. The Configuration windows allow you to specify these values. Figure 3.8 shows the Configuration window for the temperature subunit, which is similar to those for the other two sensor types.

The data in the Sensor Configuration table are read in from the "presscfg.dat" file for the pressure subunit. The "tempcfg.dat" and "tenscfg.dat" files are used for the temperature and

\begin{tabular}{|c|c|c|c|c|c|}
\hline \multicolumn{6}{|c|}{ - Configuralion:Temperature } \\
\hline Duit & & & & & \\
\hline \multirow[b]{2}{*}{ d_ } & \multicolumn{4}{|c|}{ Sensor Configuration } & \\
\hline & Well \#_ & Station \# & Multiplexer \# & Location \#__ & \\
\hline 13 & 1 & 1 & 1 & 3 & 4 \\
\hline 48 & 1 & 1 & 1 & 12 & $F$ \\
\hline 4 & 1 & 1 & 1 & 16 & 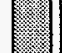 \\
\hline 49 & 1 & 1 & 2 & 3 & 12 \\
\hline 50 & 1 & 1 & 2 & 9 & F: \\
\hline 6 & 1 & 1 & 2 & 12 & W \\
\hline 3 & 1 & 1 & 2 & 15 & a \\
\hline
\end{tabular}

FIGURE 3.8 Configuration Window 
tensiometer sensors. In the unlikely event that these values need to be changed, you can edit these files by using any ASCII text editor. The two buttons on this window perform the following actions:

Quit Press this button to exit this window.

Help Press this button to bring up the help window with information on the Configuration window.

\subsection{GENERATE WINDOWS}

As the bioremediation study proceeds, it will be necessary to vary the sampling periods of the different subunits. The Generate windows allow you to recreate the datalogger programs by using new sampling periods. As shown in Figure 3.9, the Generate windows allow you to specify different time values and create a program, which is shown in a text region at the bottom of the window. The Generate windows for the three different subunits are similar.

The buttons on this window perform the following actions:

Quit

Press this button to exit this window.

Help

Press this button to bring up the help window with information on the Generate window.

Generate Press this button to regenerate the program for the given sensor type using the specified time values.

Save

Press this button to save the program to a file with the specified name.

The text options on this window record the following values:

Program file Specify the name of the file when saved.

Start time (hh:mm) Specify the time in GMT when the program should start recording sensor values. This time should be later than the current time and generally on the hour.

Execution interval Specify a real value to indicate how frequently the datalogger program should (min)

cycle and perform its commands. This real value should not be changed from its default value of 1.0 minute. 


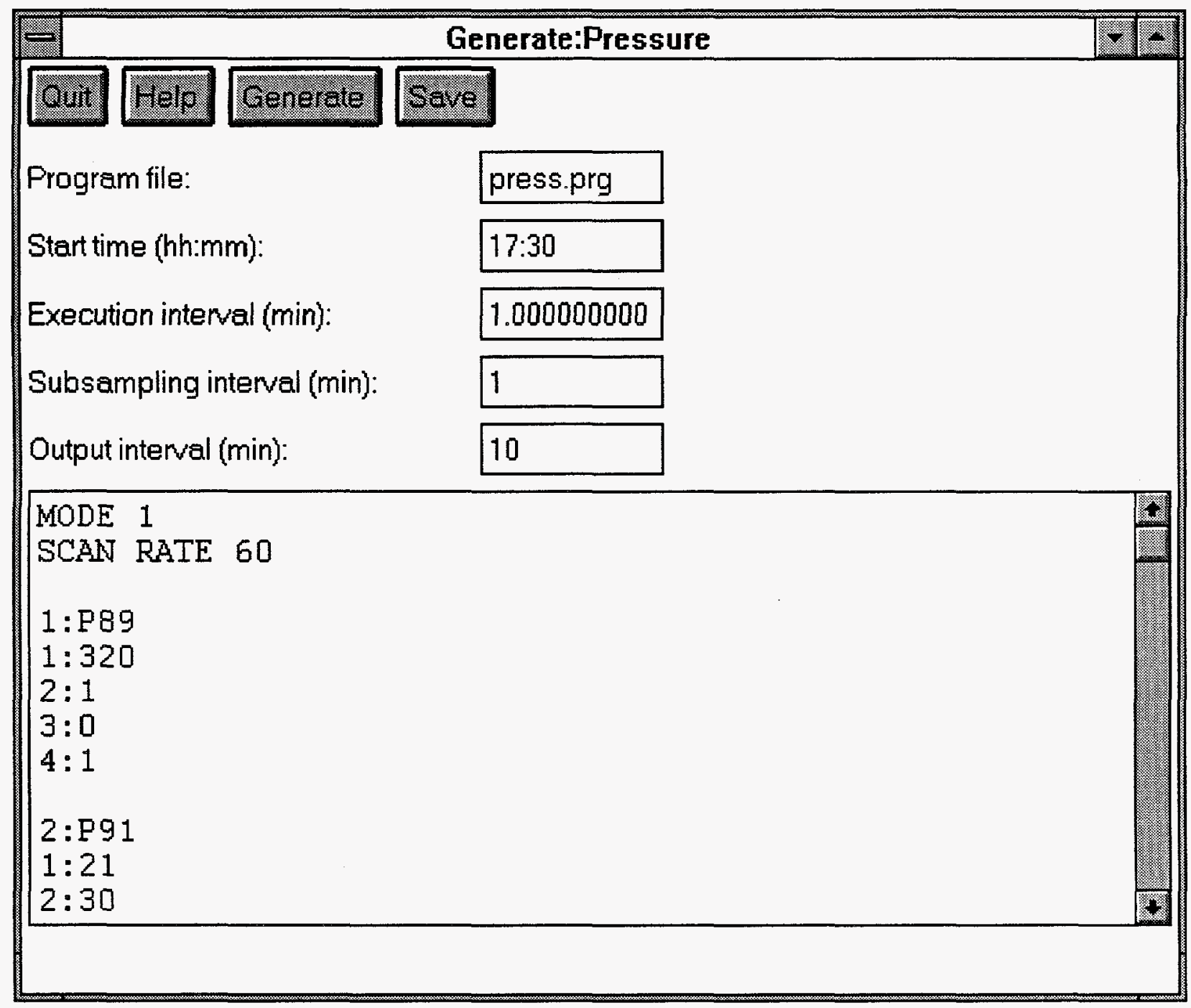

FIGURE 3.9 Generate Window

Subsampling interval (min)

Output interval (min)
Specify how often each sensor should be polled by the program. This subsample value is stored internally by the datalogger program. Generally, this integer value is 1 minute. This value must be greater than or equal to the execution interval of the program.

Specify how often the program should average the internal subsample values and record that average in the accessible ring memory area of the datalogger. The last subsample value is also output at this output time. This integer value will usually be 10,60 , or 1,440 minutes ( 1 day). This value must be greater than or equal to the subsampling interval. 
At the start of the study, the time interval values will be 1.0,10, and 60 minutes. After you enter the proper time values, create the new datalogger program by pressing the Generate button. You can review the programs generated and make changes by using the text region in the window. When the program is completed, save it by pressing the Save button before sending it to the datalogger through the Terminal window.

\subsection{TERMINAL WINDOWS}

The Terminal windows are used to communicate to a datalogger through a serial port. There are three Terminal windows, one for each subunit. As shown in Figure 3.10, these windows contain a row of buttons, several option fields, and a text region that displays the communication between the datalogger and the Datalogger Programmer. Information on these communication commands can be found in the CR10 manual.

The buttons at the top of the window perform the following actions:

Quit Press this button to exit this window.

Help Press this button to bring up the Help window with information on the Terminal window.

Ring COM Press this button to send characters to the datalogger to get it to respond to your request. Perform this action before setting the clock or sending a new program to the datalogger.

Set Clock Press this button to bring up a window to set the time of the datalogger to the same time as the PC (Section 3.7).

Send Program Press this button to send the specified program to the datalogger.

Clear Press this button to clear any old programs out of the datalogger memory.

These buttons for the option fields listed below use the following values:

Port Select the communications port used for this subunit by choosing the choice box to the left of it. These ports are initialized with data in the "portdef.dat" file and should generally not be changed. The values W1 and W2 correspond to MS Windows serial ports. Values D1 through D8 correspond to the eight Digiboard serial ports. 


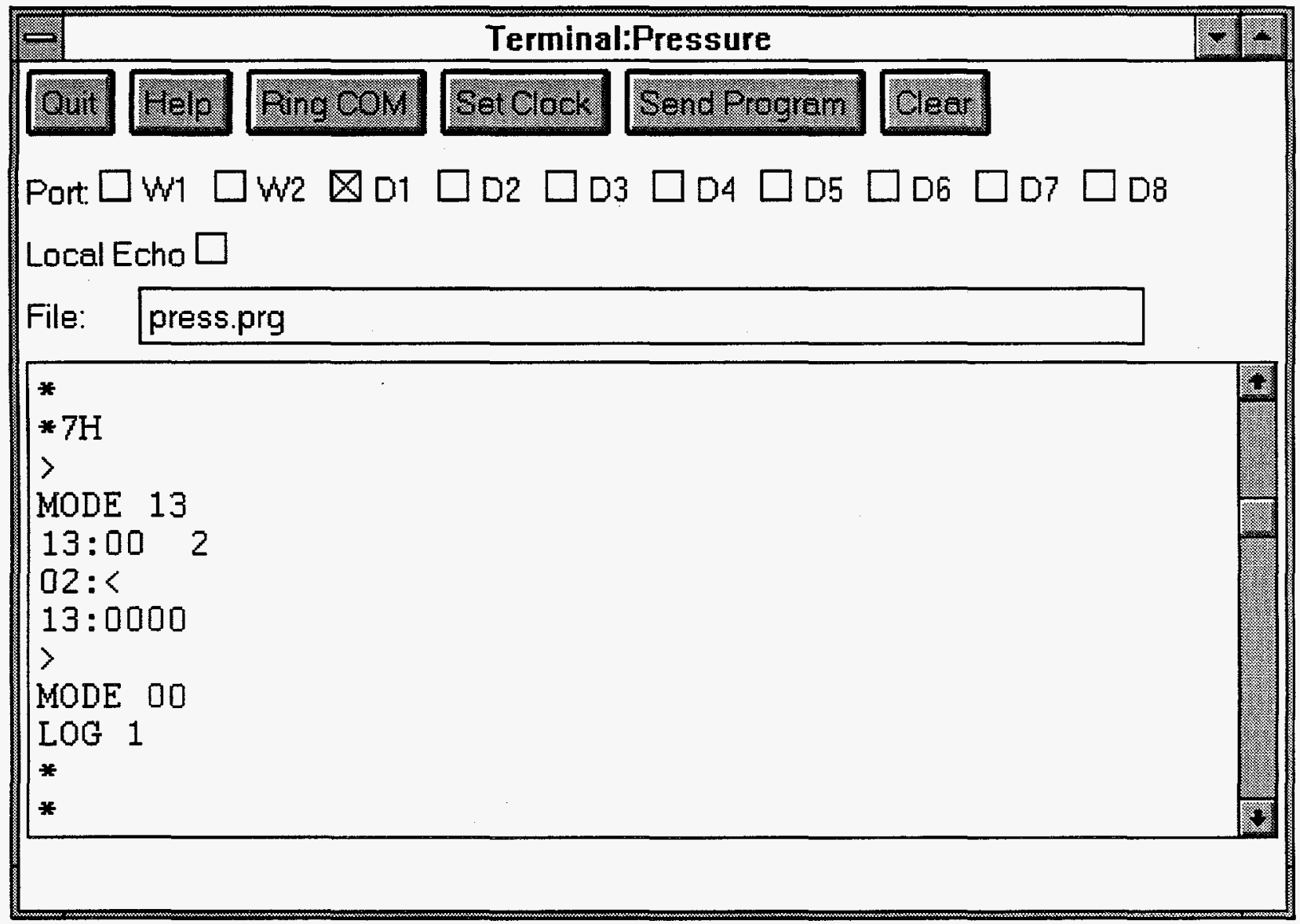

FIGURE 3.10 Terminal Window

Local Echo Select this option to indicate that all characters should be echoed in the text region. This debugging feature is not generally needed.

File:

Type in the name of the datalogger program created and saved in the Generate window.

If a program is sent to the datalogger correctly, the following characters appear in the text region on the window, as shown in Figure 3.10:

\section{MODE 00 \\ LOG 1 \\ *}

After all of the dataloggers have been reprogrammed, it is important to record the new schedule of times by selecting the Save Times option in the File menu (Section 3.2), so that the Data 
Acquirer has the correct time schedule. After the files are properly saved, a message appears in the history $\log$, as shown in Figure 3.1.

\subsection{CLOCK TIME WINDOW}

Before sending a new program to a datalogger, make sure that the times of the PC and datalogger are synchronized. When you are reprogramming the dataloggers, check these times to make sure that they are close. Slight deviations in these times are normal and will not affect the operation of the data acquisition programs. As shown in Figure 3.11, the window shows you the time on both the datalogger and the PC. If you want to reset the time on the PC, wait for a time when a reading is unexpected before exiting the Data Acquirer and MS Windows and resetting the PC's internal clock with the "time" command. See Section 3.8 for information on stopping the Data Acquirer.

The top row of buttons perform the following actions:

Quit Press this button to exit this window.

Help Press this button to bring up the help window with information on the Clock Time window.

Set Time Press this button to set the datalogger's time to be the same as that of the PC.

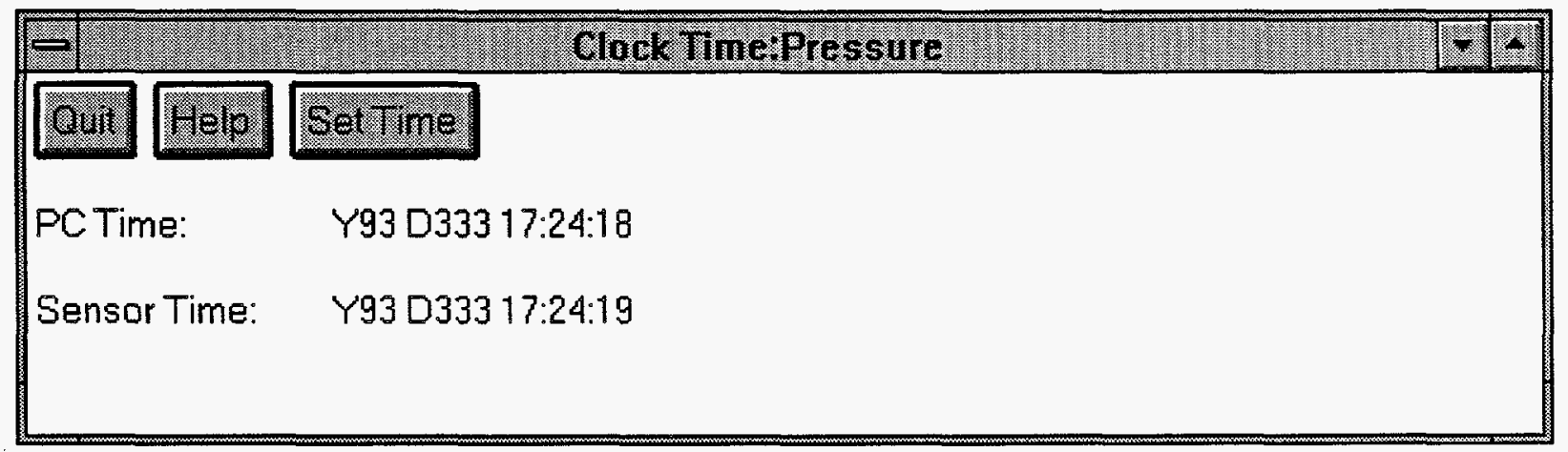

FIGURE 3.11 Clock Time Window 


\subsection{SAMPLE DATALOGGER PROGRAMMER SESSION}

This section illustrates how a sample Datalogger Programmer session may proceed. When the bioremediation analysts decide that the time intervals of the subunits need to be changed, they will request that the dataloggers be reprogrammed. Take the following steps:

- Step 1 - Stop the Data Acquirer program by pressing the Quit button in its main window.

- Step 2 - Start the Datalogger Programmer by double-clicking on the associated icon in the Sandia Project Group window of the Program Manager

- Step 3- Select the Generate option from the Temperature menu on the main window.

- Step 4 - Type the new subsampling interval and output interval in the Generate window.

- Step 5-Press the Generate button to create the program.

- Step $6-$ Type in a new filename to represent this program (for example, "temp3.prg").

- Step 7 - Press the Save button to save the program to that file.

- Step 8-Press the Quit button on the Generate window to quit that window.

- Step 9 - Select the Terminal option from the Temperature menu on the main window.

- Step 10 - Press the Ring COM button to initiate communication with the datalogger.

- Step 11 - Press the Set Clock button to check the time on the datalogger.

- Step 12 - Reset the datalogger's time, if needed, by pressing the Set Time button on the Clock Time window.

- Step 13 - Press the Quit button on the Clock Time window. 
- Step 14 - Type in the name of the new CR10 program in the File text field in the Terminal window. This name must be the same as the name used in step 6.

- Step 15 - Press the Send Program button in the Terminal window to send the new program to the datalogger. Verify that the program was correctly sent by viewing the results in the text region of the Terminal window. If successful, the statements "MODE 00" and "LOG1" will appear as shown in Figure 3.10.

- Step 16 - Press the Quit button on the Terminal Window.

- Step 17 - Repeat steps 3 through 16 for the pressure and tensiometer subunits, using different filenames for the programs you create (for example, "press3.prg" and "tens3.prg").

- Step 18 - Select the Save Times option from the File menu to save the new time schedule.

- Step 19 - Select the Save History option from the File menu to save the log.

- Step 20 - Print out the file "c:Idatalhistory. $\log ^{\text {" }}$ by using the "net print" command in a DOS shell or by using the File Manager tool under MS Windows. Save this file in the log book.

- Step 21 - Select the Close option from the File menu to quit the Datalogger Programmer.

- Step 22 - Start the Data Acquirer again so that it will use the new values. This process is discussed in Section 4.2.

- Step 23 - Verify that the new readings are being read by the dataloggers by checking the equipment at the uphole equipment building and observing the behavior of the Data Acquirer. 


\section{DATA ACQUIRER}

\subsection{DATA ACQUIRER OVERVIEW}

The Data Acquirer program retrieves data from the dataloggers in the sensor subunits. By using the schedule recorded in the "temp.lst," "press.lst," and "tens.lst" files, the program waits for the correct time and uses CR 10 commands to retrieve data from the subunits. Each datalogger is attached to a serial port on the PC through RS 232 lines with short-haul modems. After being programmed through the Datalogger Programmer, the dataloggers record sensor values in their ring memory area. When a scheduled time arrives, the Data Acquirer automatically issues the appropriate commands to read this memory area and writes the data out to data files in the data directory. These files are named on the basis of their time, date, and sensor type, as shown in the Figure 4.1. For example, the file named "1300120.p94" corresponds to the pressure data for April 30, 1994, at 13:00 GMT. The subunits for temperature, pressure, and tensiometer correspond to the sensor type designators "t," "p," and "d." The Appendix contains two tables listing the Julian days, which are used to represent the date in the file names. One table is used for leap years, and the other for nonleap years.

\subsection{DATA ACQUIRER WINDOW}

The main window of the Data Acquirer program is shown in Figure 4.2. To bring up the program, double-click on the corresponding icon in the Sandia Project Group window (Figure 2.3). Generally, no other actions are needed. After reading in the schedule of times and communication port identifiers, the program enters a loop and waits for the next scheduled time. The main window

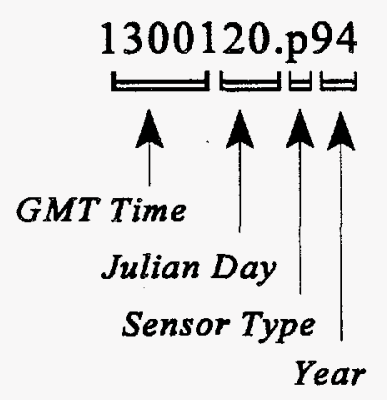

FIGURE 4.1 Data File Naming Convention 


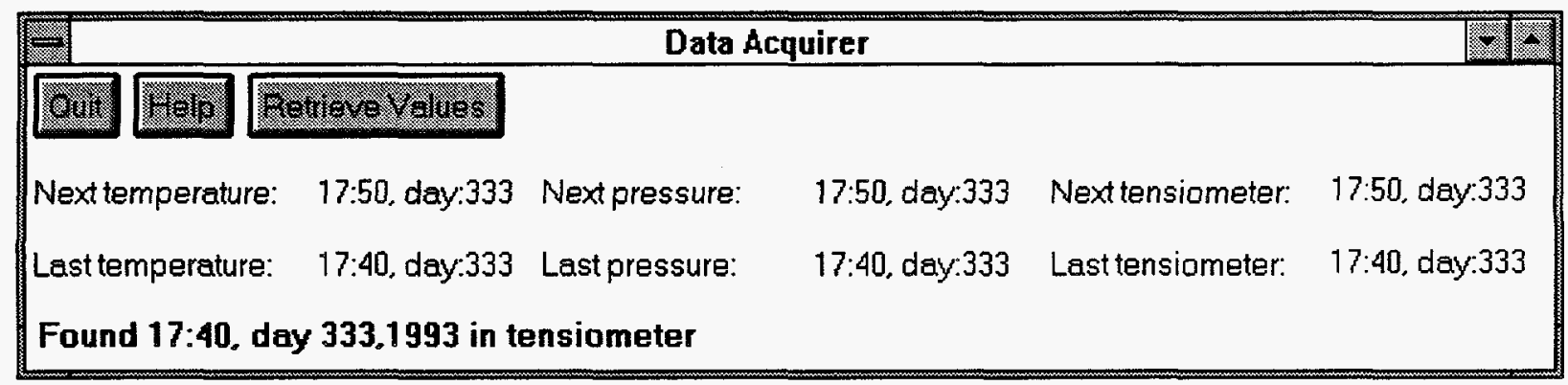

FIGURE 4.2 Data Acquirer Window

contains a row of buttons and several rows of time values. These text values show the time when the data file of each sensor type was last read and the times of the next scheduled readings. The footer message area (across the bottom of the window) gives information on the progress of the retrieval process. These messages are also displayed in the Sensor Monitor log (Section 5). If a reading is missed because of a hardware or software problem, use the options in the program to manually retrieve the sensor data.

The buttons at the top of the window can be used as follows:

Quit Press this button to exit the program.

Help Press this button to bring up the Help window with information on the Data Acquirer main window.

Retrieve Values Press this button to bring up the Retrieve Values window to retrieve values that were not recorded correctly because of some problem such as a power failure.

The program will continuously make readings according to the specified schedule. As each reading is made, several actions occur: (1) the data file is created in the data directory, (2) the text fields in the window are updated, (3) the footer message indicates that the data were found, (4) the same message is sent to the Sensor Monitor program, and (5) the data file is copied to the Sun data analysis workstation. As the file is copied to the workstation, an icon labeled "copy" will appear at the bottom of the window (Figure 1.1). If this icon remains on the screen for more than a few moments, the PC-NFS communication link may be experiencing problems.

If the Data Acquirer attempts to read the data for a certain time period while the datalogger is still reading the sensors for that time, a warning is displayed in the footer message area of the window. This message, which states that the Data Acquirer was unable to find that reading, is only a warning and not a cause for alarm, since the Data Acquirer will attempt to make the reading again 
after a minute has elapsed. If a significant amount of time passes (for example, 10 minutes) and the reading has still not been made, there may be a problem with the RS232 line or the datalogger. Check the uphole equipment building to see if the subunits are still active. (Listen for the clicking noise caused by the cycling of the multiplexers.)

\subsection{RETRIEVE VALUES WINDOW}

The Retrieve Values window is shown in Figure 4.3. If the Data Acquirer fails to record data values because of a power failure or system error, this window can be used to manually trigger the program to access the datalogger and retrieve a specified set of data values, if they are still within the ring memory area of the datalogger. Because the datalogger has a small amount of external memory organized as a ring, it can store several days' worth of data before older data are overwritten. Each data set on a datalogger is preceded and followed by a date stamp that identifies it.

The Retrieve Values window has a row of buttons that perform the following actions:

Quit Press this button to exit this window.

Help Press this button to bring up the Help window with information on the Retrieve Values window.

Retrieve Press this button to retrieve a set of data values.

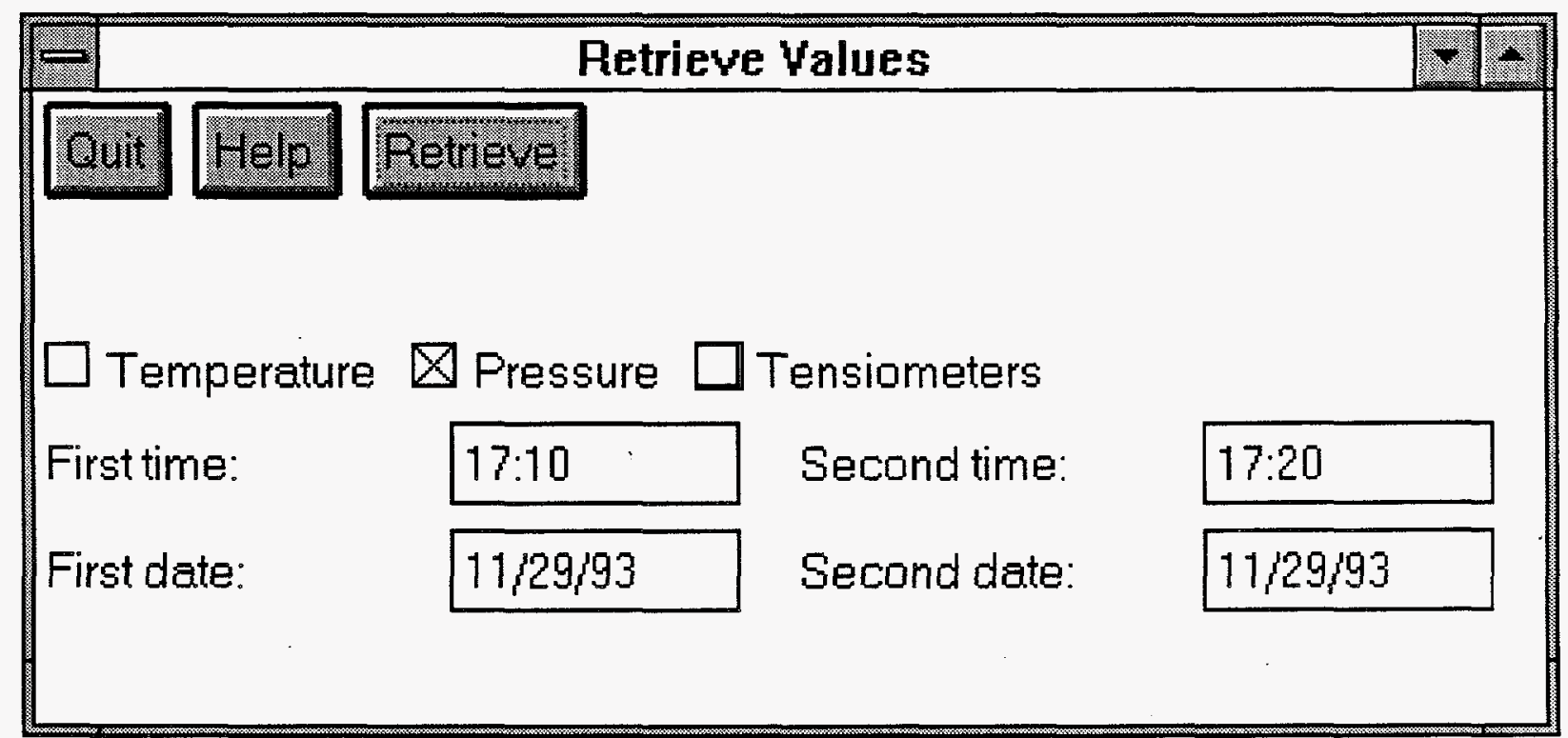

FIGURE 4.3 Retrieve Values Window 
To specify the type of data and time range, use the choice option and text fields in the lower part of the window. Only one datalogger can be accessed at a time; if more than one type of sensor data are needed, repeat the process for each. It is important to note that if an incorrect time range is specified in the text fields, the program checks all of the datalogger memory, which takes several minutes. Do not attempt to interrupt this process; wait until it is finished before entering the correct days.

\subsection{SAMPLE DATA ACQUIRER SESSION}

This section describes the steps to manually retrieve data values with the Data Acquirer.

- Step 1 - Start the Data Acquirer, if necessary, by double-clicking on the corresponding icon in the Sandia Project Group window of Program Manager. (Unless you are using the Datalogger Programmer to reprogram the dataloggers, the Data Acquirer should be running.)

- Step $2-$ Verify that the text fields in the main window show the correct next scheduled reading times.

- Step 3-Wait until either a reading has just occurred or no automatic reading is scheduled for several minutes. Waiting ensures that the manual retrieval process will not interfere with an automatic scheduled retrieval.

- Step 4 - Press the Retrieve Values button to bring up the Retrieve Values window.

- Step 5-Select the choice option corresponding to the first type of sensor subunit for which you want to retrieve data.

- Step 6 - Type in the time and date values for the time range for which data were missing.

- Step 7 - Press the Retrieve button to cause the Data Acquirer to look for those readings.

- Step 8 - Verify that the program displays a message that indicates the value has been found.

- Step 9 - Select the choice option for next type of sensor and repeat step 7, as needed. 
- Step 10 - Press the Quit button to exit the Retrieve Values window. The Data Acquirer program continues to run.

- Step 11 - Use the File Manager or a DOS shell to verify that the new data files now reside in the data directory. Filenames follow the naming convention described in Section 4.1. Use the following DOS command to view a file listing of the pressure directory on the PC:

\section{dir c:ldataldatalpress}

- Step 12 - To verify that the files were correctly transferred to the Sun, use the same procedure to view the files on the data directory on the Sun:

dir f: Thaw0ldata 


\section{DATA UPLOAD}

\subsection{DATA UPLOAD OVERVIEW}

The Data Upload program was designed to copy files to the Sun workstation if, for some reason, the Data Acquirer did not copy the files. Under normal circumstances, this program is not needed; it would be used only if the Sun workstation were disconnected from the PC for a period of time (for example, because of a hardware problem). After the Sun workstation is reattached, run this program to manually copy selected files to the Sun. The MS Windows File Manager or a DOS shell should be used for copying large numbers of files. This program can also be used to view a directory of the data files on a specific day.

\subsection{DATA UPLOAD WINDOW}

To start the Data Upload program, double-click on the corresponding icon in the Sandia Project Group window of the Program Manager (Figure 2.3). The Data Upload program contains the window shown in Figure 5.1.

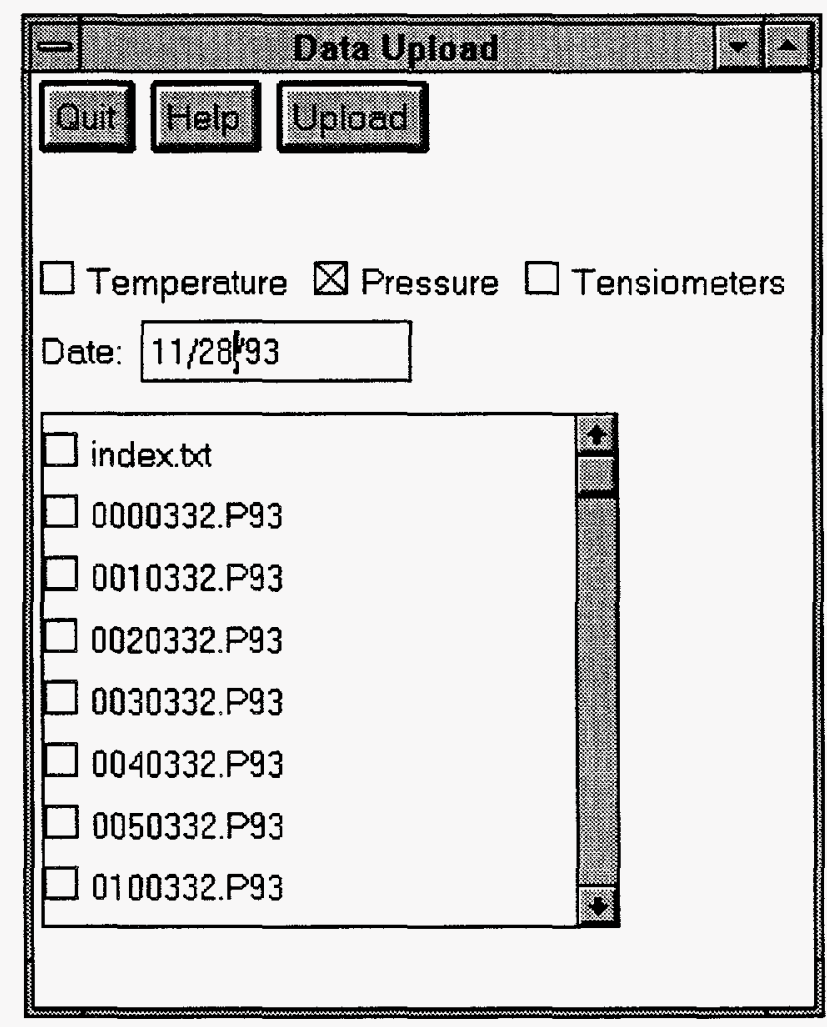

FIGURE 5.1 Data Upload Window 
The buttons perform the following actions:

Quit Press this button to exit this window.

Help Press this button to bring up the help window with information on the Data Upload window.

Upload Press this button to copy the files selected in the scrolling area to the data directory on the Sun.

After you have typed the desired date in the text field and selected the choice option for the desired sensor type, the corresponding data files will be listed in the scrolling area at the bottom of the window. Select the choice box preceding the filename to choose files for copying. After you have pressed the Upload button, each file is copied to the Sun workstation. The directory on the Sun workstation can be changed by changing the command line option specified for the Data Upload icon in the Sandia Project Group window of the Program Manager. 


\section{SENSOR MONITOR}

\subsection{SENSOR MONITOR OVERVIEW}

The Sensor Monitor program monitors the status of readings made by the Data Acquirer program. After each reading is made, the Data Acquirer sends a message on the updated status to the Sensor Monitor. This readings $\log$ can be used to keep track of the process. A daily $\log$ is automatically printed by the program.

\subsection{SENSOR MONITOR WINDOW}

The Sensor Monitor is invoked by double-clicking on the corresponding icon in the Sandia Project Group window of the Program Manager (Figure 2.3). The main window of the Sensor Monitor is shown in Figure 6.1. A scrolling region displays the history of readings made by the Data Acquirer. At the end of each day (GMT time), this log is saved to a data file with the form shown in Figure 6.2.

This file is automatically printed, so that it can be checked and stored in the records. The $\log$ is then set to the new day, and the process continues.

The buttons in the window perform the following actions:

Quit

Help

Print

Clear

Load
Press this button to exit the program.

Press this button to bring up the Help window with information on the Sensor Monitor window.

Press this button to print the current log to the printer connected on the network.

Press this button to clear out the $\log$ in the window.

Press this button to load in the log for the current day (daily.log). 


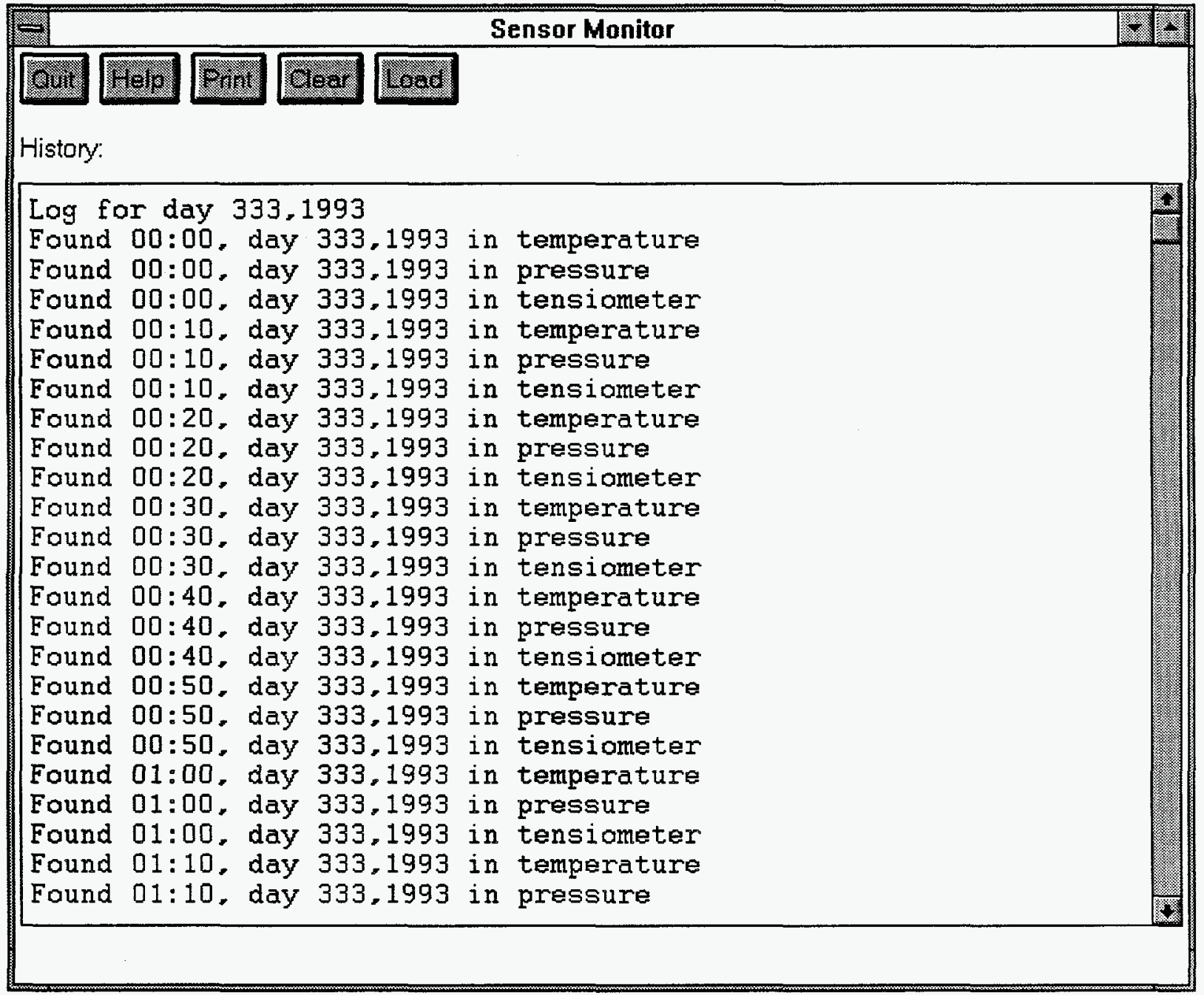

FIGURE 6.1 Sensor Monitor Window

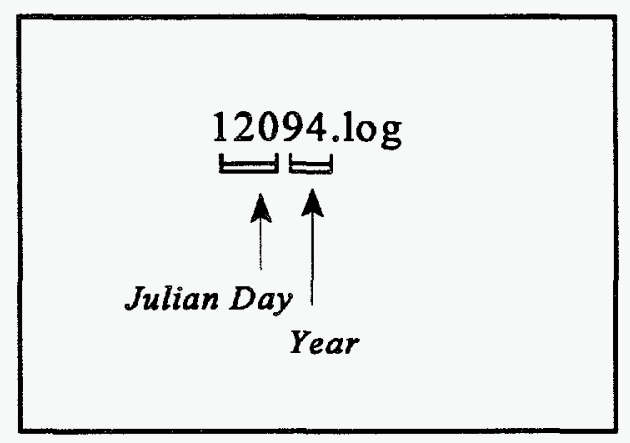

FIGURE 6.2 Log File Names 
APPENDIX:

JULIAN DAY CONVERSION TABLES 


\begin{tabular}{|c|c|c|c|c|c|c|c|c|c|c|c|c|}
\hline $\bar{m}$ & $\vec{m}$ & & 8 & & $\bar{n}$ & & $\frac{\pi}{\sqrt{N}}$ & $\stackrel{\text { J }}{\mathrm{N}}$ & & ষ্ల & & 点 \\
\hline ק् & 요 & & ஜ & 옹 & 도 & $\Phi$ & $\overline{\bar{N}}$ & $\stackrel{\sim}{\sim}$ & $\frac{m}{n}$ & 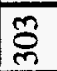 & m & ఫ্ల \\
\hline สิ & 이 & & $\infty$ & $\stackrel{9}{\Xi}$ & g & $\nsubseteq$ & $\frac{O}{2}$ & $\vec{\sim}$ & $\stackrel{\widetilde{N}}{\sim}$ & ণ্লি & ले & ల్ల \\
\hline$\stackrel{\infty}{\infty}$ & $\stackrel{\infty}{\sim}$ & in & $\infty$ & $\stackrel{\infty}{=}$ & $\stackrel{\infty}{ \pm}$ & I & 웟 & 웜 & $\bar{N}$ & $\vec{\rho}$ & ma & ర్ల \\
\hline 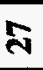 & $\hat{\sim}$ & $\infty$ & $\triangleright$ & $\Xi$ & 更 & $\stackrel{\infty}{\underline{\Sigma}}$ & 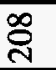 & & $\underset{\sim}{\stackrel{ }{N}}$ & 요 & $\bar{m}$ & $\bar{b}$ \\
\hline i̊ & ర్ల & in & $\curvearrowleft$ & $\stackrel{0}{\varrho}$ & I & $E$ & $\bar{d}$ & $\underset{\sim}{\infty}$ & 总 & g. & लि & 융 \\
\hline$\stackrel{\leftrightarrow}{*}$ & $\approx$ & ஜூ & ষ & $\cong$ & $\stackrel{y}{q}$ & $\stackrel{0}{2}$ & 로 & $\widehat{\tilde{N}}$ & 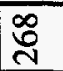 & 㐫 & 객 & 鬲 \\
\hline$\vec{N}$ & $\stackrel{\sim}{\sim}$ & $n$ & $\ddot{\infty}$ & $\Xi$ & 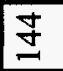 & $\underline{n}$ & ర్d & i̊ & 유 & î̀ & $\begin{array}{l}\infty \\
\text { N } \\
\text { }\end{array}$ & $\begin{array}{l}\infty \\
m \\
m\end{array}$ \\
\hline$\tilde{\sim}$ & $\tilde{\curvearrowright}$ & $\dot{n}$ & $\lesssim$ & $\stackrel{m}{=}$ & $\stackrel{m}{ \pm}$ & \pm & ర্] & $\hat{\tilde{n}}$ & 品 & :ั & ले & $\sqrt{n}$ \\
\hline $\mathcal{N}$ & $\mathcal{N}$ & $\tilde{n}$ & $\bar{\infty}$ & $\cong$ & $\stackrel{\mathcal{I}}{ \pm}$ & $\cong$ & ల్లి & $\vec{\Theta}$ & బ్ & 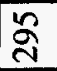 & 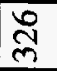 & 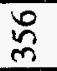 \\
\hline $\bar{\pi}$ & $\bar{N}$ & in & $\infty$ & $\Xi$ & $\Xi$ & $\cong$ & ণิ & & $\underset{\sim}{\mathbb{S}}$ & মั & $\stackrel{2}{n}$ & $\begin{array}{l}n \\
m \\
m\end{array}$ \\
\hline శ్ & 요 & $\bar{n}$ & 9 & $\stackrel{ }{\varrho}$ & 导 & $\Xi$ & $\bar{్}$ & $\widehat{\widetilde{N}}$ & $\hat{\mathcal{N}}$ & g̊ & 志 & 点 \\
\hline 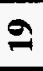 & $\stackrel{2}{2}$ & in & $\stackrel{\infty}{\sim}$ & 8 & 용 & 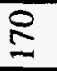 & $\underset{\text { }}{8}$ & $\overrightarrow{\vec{n}}$ & i్ర & নิ & तె & ñ \\
\hline$\cong$ & $\stackrel{\infty}{=}$ & g & $\approx$ & $\stackrel{\infty}{\varrho}$ & $\stackrel{\infty}{\varrho}$ & 음 & $\stackrel{\Omega}{\Omega}$ & ֶ. & $\bar{\sim}$ & $\bar{a}$ & N & 放 \\
\hline$\Xi$ & $\Xi$ & $\stackrel{\infty}{\forall}$ & $\stackrel{\circ}{\circ}$ & 5 & $\tilde{m}$ & $\stackrel{\infty}{\circ}$ & $\stackrel{\infty}{2}$ & શิ & 8 & 足 & $\bar{N}$ & $\overline{\tilde{n}}$ \\
\hline 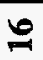 & $\mathscr{O}$ & F & $\approx$ & $\mathscr{g}$ & 品 & So & 5 & $\underset{\sim ్}{\infty}$ & है & : & 융 & 号 \\
\hline In & $n$ & \& & 怘 & $\stackrel{8}{0}$ & $\underline{m}$ & 8 & פ̊ & $\overline{\mathrm{N}}$ & $\stackrel{\infty}{n}$ & 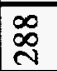 & $\frac{9}{m}$ & 兴 \\
\hline \pm & \pm & $\stackrel{n}{q}$ & $m$ & $\stackrel{\Xi}{\Xi}$ & $\stackrel{\Xi}{m}$ & 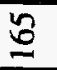 & $\approx$ & 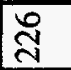 & $\sqrt{n}$ & 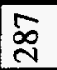 & $\frac{\infty}{\infty}$ & 㐫 \\
\hline$\stackrel{m}{2}$ & 9 & 寸 & $\mathbb{N}$ & 8 & $\underline{m}$ & to & ఫે & ฟิ & 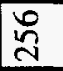 & 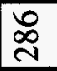 & $\frac{N}{m}$ & 誉 \\
\hline$\underline{\mathcal{I}}$ & $\simeq$ & $\ddot{q}$ & $\bar{F}$ & $\tilde{\sigma}$ & $\stackrel{2}{m}$ & 8 & $\Omega$ & $\underset{\underset{N}{ }}{\mathbb{N}}$ & $\approx$ & 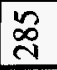 & $\frac{\circ}{m}$ & 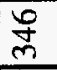 \\
\hline$\exists$ & $\Rightarrow$ & $\stackrel{Y}{y}$ & $R$ & $\bar{\varrho}$ & $\bar{m}$ & ช్ & $\Omega$ & तิ & 营 & 芯 & $\frac{m}{m}$ & 学 \\
\hline 으 & 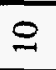 & $\vec{F}$ & 8 & 8 & 음 & $\bar{\sigma}$ & $\bar{\Omega}$ & הี & $\tilde{n}$ & 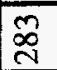 & $\frac{d}{m}$ & 离 \\
\hline$a$ & $a$ & 아 & $\infty$ & a & ㄱ. & 8 & 8 & $\overline{\tilde{N}}$ & $\tilde{~}$ & 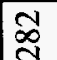 & $\frac{m}{m}$ & $\stackrel{m}{f}$ \\
\hline$\infty$ & $\infty$ & m & $\sqrt{6}$ & $\infty$ & 文 & $\stackrel{2}{2}$ & ஓ & 웟 & $\bar{n}$ & $\bar{\infty}$ & $\frac{N}{M}$ & $\mathscr{\mathcal { F }}$ \\
\hline$n$ & $N$ & $\infty$ & 8 & 5 & $\bar{\beth}$ & $\stackrel{\infty}{\Omega}$ & $\stackrel{\infty}{\infty}$ & $\frac{\partial}{2}$ & ஜֶ & $\stackrel{\infty}{\infty}$ & $\bar{m}$ & $\bar{f}$ \\
\hline 6 & b & n & 6 & \% & $\stackrel{\text { ్ }}{=}$ & n & $\infty$ & $\frac{\infty}{\sim}$ & 亲 & $\frac{2}{2}$ & $\frac{O}{m}$ & 昌 \\
\hline in & $n$ & m & $\mathbb{J}$ & 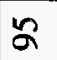 & $\mathfrak{\Xi}$ & $\stackrel{\circ}{\check{2}}$ & 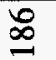 & $\frac{\pi}{2}$ & 文 & $\stackrel{\infty}{\underset{N}{*}}$ & \&్లి & बे \\
\hline$\nabla$ & $\nabla$ & $\tilde{m}$ & $\tilde{3}$ & J & $\stackrel{\mathbb{I}}{\mathbf{I}}$ & 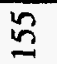 & $\infty$ & $\frac{0}{2}$ & 寽 & $\underset{\text { N }}{\text { S }}$ & $\stackrel{\infty}{\circ}$ & $\stackrel{\infty}{m}$ \\
\hline$m$ & $m$ & mे & ชె & $\tilde{\alpha}$ & $\tilde{\Xi}$ & 莺 & $\underset{\sim}{\mathbb{Z}}$ & $\frac{n}{n}$ & 每 & $\frac{1}{2}$ & চ্ & $\hat{m}$ \\
\hline$N$ & $N$ & $m$ & $\overline{0}$ & ๙ু & $\tilde{\Xi}$ & $\tilde{\Omega}$ & $\infty$ & $\frac{\nabla}{N}$ & $\stackrel{\text { I }}{d}$ & $\stackrel{n}{2}$ & \& & D্ \\
\hline$\Rightarrow$ & - & N & 8 & $\bar{a}$ & $\bar{\Xi}$ & iv & $\underset{\infty}{\infty}$ & $\frac{m}{N}$ & $\underset{d}{J}$ & $\underset{N}{\mathbb{N}}$ & 点 & $m$ \\
\hline & 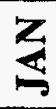 & 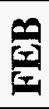 & $\stackrel{\Sigma}{\xi}$ & $\stackrel{\mathscr{a}}{\not}$ & $\$$ & 孞 & $\underline{5}$ & $\underset{4}{3}$ & 氙 & 8 & 8 & 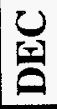 \\
\hline
\end{tabular}




\begin{tabular}{|c|c|c|c|c|c|c|c|c|c|c|c|c|}
\hline$\overline{\text { ले }}$ & $\vec{m}$ & & $\bar{a}$ & & ก & & $\frac{m}{\mathrm{~N}}$ & $\stackrel{7}{7}$ & & 总 & & : \\
\hline ల్ల & 요 & & 8 & $\bar{\Xi}$ & $\bar{n}$ & $\stackrel{\infty}{\infty}$ & $\frac{N}{d}$ & $\stackrel{m}{\sim}$ & $\underset{⿱}{\stackrel{\Delta}{*}}$ & ষ্ল & $m$ & bi \\
\hline สิ & Дิ & 8 & $\infty$ & 요 & 으 & $\ddot{\infty}$ & $\overline{\bar{\lambda}}$ & $\underset{\sim}{\stackrel{N}{\sim}}$ & $\stackrel{\tilde{N}}{\mathrm{~N}}$ & ల్ & ले & ర్ల \\
\hline 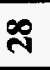 & $\stackrel{\infty}{\sim}$ & हn & $\infty$ & 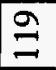 & $\stackrel{g}{ \pm}$ & 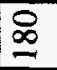 & $\frac{\text { 임 }}{\sim}$ & $\vec{d}$ & $\stackrel{\mathbb{N}}{\sim}$ & S్ & $\stackrel{m}{m}$ & గ్ల \\
\hline$\lesssim$ & $\tilde{\lambda}$ & $\stackrel{\infty}{n}$ & $\infty$ & $\stackrel{\infty}{\Xi}$ & $\stackrel{\infty}{ \pm}$ & $\stackrel{9}{2}$ & 옥 & 요 & $\bar{\lambda}$ & $\overrightarrow{D_{n}}$ & ले & స్ల \\
\hline ปั & I & $n$ & $\infty$ & $\Xi$ & $\exists$ & $\stackrel{\infty}{\Xi}$ & $\stackrel{8}{\circ}$ & & 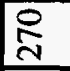 & 8 & $\bar{m}$ & $\bar{n}$ \\
\hline జn & 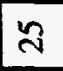 & in & 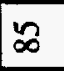 & $\underline{O}$ & I & $\Xi$ & S్తి & $\begin{array}{l}\infty \\
\tilde{N}\end{array}$ & 命 & 옥 & m & 8 \\
\hline$\vec{N}$ & $\vec{\sim}$ & $n$ & 怘 & $\cong$ & 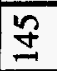 & $\stackrel{2}{2}$ & ర్ల. & $\widehat{\widehat{~}}$ & 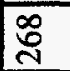 & $\stackrel{\infty}{\stackrel{\aleph}{人}}$ & i্লি & 弇 \\
\hline$\ddot{\sim}$ & กิ & $\ddot{n}$ & $\infty$ & $\Xi$ & \pm & $\stackrel{n}{2}$ & 定 & లి & $\sqrt{\mathcal{N}}$ & 곡 & 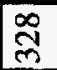 & $\begin{array}{l}\infty \\
n \\
n\end{array}$ \\
\hline ה & 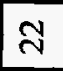 & $\tilde{n}$ & $\infty$ & $\stackrel{m}{\Xi}$ & $\stackrel{?}{ \pm}$ & \pm & 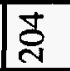 & $\tilde{\tilde{n}}$ & 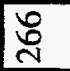 & \&̊ำ & तె & $n$ \\
\hline $\bar{N}$ & $\vec{\sim}$ & ก & $\bar{\infty}$ & $\cong$ & 寽 & $\stackrel{m}{=}$ & 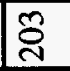 & సे & 总 & 공 & 品 & nn \\
\hline తิ & గి & $\bar{n}$ & $\infty$ & $\Xi$ & $\Xi$ & $\underline{I}$ & 웡 & $\hat{\tilde{N}}$ & $\stackrel{d}{d}$ & ㄱ. & $\stackrel{n}{n}$ & 党 \\
\hline$\theta$ & $\stackrel{9}{=}$ & 으 & 2 & $\stackrel{\varrho}{\Xi}$ & I & $\Xi$ & $\overline{\tilde{d}}$ & $\stackrel{\widetilde{N}}{\widetilde{N}}$ & $\hat{\mathscr{d}}$ & กิ่ & 志 & $\stackrel{⿱ 亠}{n}$ \\
\hline$\stackrel{\infty}{=}$ & $\stackrel{\infty}{=}$ & gq & $\stackrel{\infty}{\sim}$ & 8 & $\ddot{m}$ & $\stackrel{8}{2}$ & 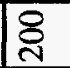 & $\overline{\vec{c}}$ & ర్d & $\widehat{\widehat{N}}$ & $\tilde{\curvearrowright}$ & लి \\
\hline$\Xi$ & $=$ & $\stackrel{\infty}{+}$ & $E$ & $\mathscr{\infty}$ & $\stackrel{\infty}{\stackrel{\infty}{m}}$ & 8 & 2 & ్ㅛ & $\overrightarrow{\mathrm{d}}$ & $\overrightarrow{\bar{d}}$ & & ผ \\
\hline$\stackrel{\theta}{0}$ & $\stackrel{0}{-1}$ & F & $\stackrel{0}{\circ}$ & 5 & $\underline{m}$ & 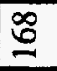 & $\stackrel{\infty}{\varrho}$ & సิ & 8 & 욤 & $\bar{\kappa}$ & $\bar{n}$ \\
\hline 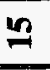 & $\cong$ & $\mathscr{q}$ & $\approx$ & \& & $\stackrel{\text { m }}{2}$ & $\underline{0}$ & ఏ & $\underset{\sim}{\text { స్ }}$ & ฉิ) & 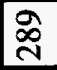 & ন্ & 욤 \\
\hline \pm & $\Xi$ & $\stackrel{n}{\sigma}$ & I & 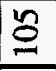 & $\tilde{m}$ & 8 & \& & $\hat{\widetilde{N}}$ & 文 & 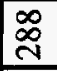 & $\frac{9}{m}$ & 守 \\
\hline $\mathscr{g}$ & $\stackrel{m}{=}$ & \& & $\stackrel{m}{\sigma}$ & $\stackrel{\Xi}{\Xi}$ & 志 & 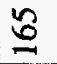 & $\stackrel{2}{\cong}$ & స్తి & $\sqrt{\tilde{n}}$ & $\infty$ & $\frac{\infty}{m}$ & $\stackrel{\infty}{\stackrel{m}{m}}$ \\
\hline 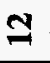 & $\simeq$ & $\stackrel{9}{4}$ & $\mathbb{N}$ & $\stackrel{\rho}{\varrho}$ & $\ddot{m}$ & $\underset{0}{Z}$ & $\$$ & $\tilde{\Xi}$ & $\mathscr{W}$ & $\underset{\sim}{\infty}$ & $\frac{\bar{m}}{2}$ & जे \\
\hline$\exists$ & $\equiv$ & 尔 & $\approx$ & S & $\stackrel{\sim}{m}$ & 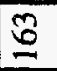 & $\Omega$ & $\underset{\mathbf{J}}{\mathbf{J}}$ & n & 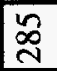 & $\frac{0}{m}$ & 㐫 \\
\hline 윽 & 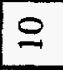 & 7 & $\stackrel{R}{2}$ & 흥 & $\bar{m}$ & $\tilde{\sigma}$ & $\underline{\Omega}$ & $\stackrel{\widetilde{N}}{\widehat{N}}$ & $\stackrel{\varpi}{~}$ & 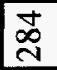 & $\frac{n}{m}$ & 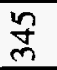 \\
\hline a & $a$ & 웅 & 8 & 8 & 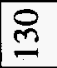 & $\overline{0}$ & $\overline{2}$ & $\underset{\sim}{\mathbb{N}}$ & $\tilde{\tilde{n}}$ & 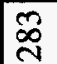 & $\frac{\vec{m}}{\mathrm{~m}}$ & 胥 \\
\hline$\infty$ & $\infty$ & gn & $\infty$ & 으 & 고 & 8 & $\&$ & $\overline{\mathrm{N}}$ & $\tilde{n}$ & 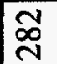 & $\frac{m}{m}$ & 鬲 \\
\hline$n$ & $r$ & $\stackrel{\infty}{\infty}$ & 5 & $\stackrel{\infty}{\circ}$ & $\stackrel{\infty}{=}$ & ig & $\infty$ & ঙ্ণী & $\vec{n}$ & $\vec{\infty}$ & $\frac{a}{m}$ & 芦 \\
\hline 0 & 0 & n & 8 & 5 & 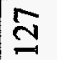 & $\stackrel{\infty}{=}$ & $\stackrel{\infty}{\infty}$ & $\frac{\partial}{\sim}$ & 목 & 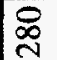 & $\bar{m}$ & $\overline{\bar{m}}$ \\
\hline n & $n$ & 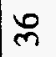 & 18 & ㅇํㄱ & $\stackrel{D}{\beth}$ & $\tilde{n}$ & $\infty$ & $\stackrel{\infty}{\sim}$ & 亭 & $\frac{2}{2}$ & $\frac{O}{m}$ & 早 \\
\hline$\nabla$ & $\nabla$ & $\tilde{m}$ & $\mathbb{J}$ & 2 & $\cong$ & $\stackrel{0}{10}$ & 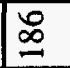 & 긍 & 文 & $\frac{\infty}{\sqrt{*}}$ & हे & ले \\
\hline$m$ & $m$ & $\vec{m}$ & 3 & ‡ & 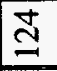 & $\approx$ & $\infty$ & $\frac{0}{2}$ & $\underset{\sim}{\stackrel{9}{4}}$ & E & $\stackrel{\infty}{8}$ & $\begin{array}{l}\infty \\
m \\
m\end{array}$ \\
\hline N & $N$ & $m$ & ک & \% & $\ddot{\Xi}$ & $\stackrel{ \pm}{n}$ & $\underset{\Xi}{ \pm}$ & $\frac{n}{2}$ & 莫 & $\stackrel{0}{\sim}$ & S్ల & $\hat{m}$ \\
\hline$=$ & - & ले & $\vec{b}$ & ๙ & త్ & $\hat{\tilde{n}}$ & $\infty$ & $\frac{\Delta}{\sim}$ & $\stackrel{n}{d}$ & $\frac{n}{2}$ & ஓ̊ & ల్లn \\
\hline & $\mathbb{Z}$ & E & $\sum$ & $\frac{\alpha}{2}$ & $\sum$ & Z & 官 & $\underset{b}{0}$ & $\frac{\sigma}{6}$ & 8 & 8 & 밈 \\
\hline
\end{tabular}

